\title{
Heat and Mass Transport in Heat Pipe Wick Structures
}

Brian D. Iverson

Brigham Young University - Provo, bdiverson@byu.edu

Tyler W. Davis

Purdue University

Suresh V. Garimella

Purdue University, sureshg@purdue.edu

Mark T. North

Thermacore International Inc.

Sukhvinder S. Kang

Aavid Thermalloy LLC

Follow this and additional works at: https://scholarsarchive.byu.edu/facpub

Part of the Chemical Engineering Commons

\section{Original Publication Citation}

Brian D. Iverson, Tyler W. Davis, Suresh V. Garimella, Mark T. North, and Sukhvinder S. Kang. "Heat and Mass Transport in Heat Pipe Wick Structures", Journal of Thermophysics and Heat Transfer, Vol. 21, No. 2 (2007), pp. 392-404. doi: 10.2514/1.25809.

\section{BYU ScholarsArchive Citation}

Iverson, Brian D.; Davis, Tyler W.; Garimella, Suresh V.; North, Mark T.; and Kang, Sukhvinder S., "Heat and Mass Transport in Heat Pipe Wick Structures" (2007). Faculty Publications. 1581.

https://scholarsarchive.byu.edu/facpub/1581 


\title{
Heat and Mass Transport in Heat Pipe Wick Structures
}

\author{
Brian D. Iverson, Tyler W. Davis and Suresh V. Garimella* \\ Cooling Technologies Research Center, Purdue University, West Lafayette, IN 47907 \\ Mark T. North \\ Thermacore International Inc., Lancaster, PA 17601 \\ and \\ Sukhvinder S. Kang \\ Aavid Thermalloy LLC, Concord, $\mathrm{NH} 03301$
}

\begin{abstract}
A novel experimental approach is developed for characterizing the performance of heat pipe wick structures. This approach simulates the actual operation of wick structures in a heat pipe. Open, partially submerged, sintered copper wicks of varying pore size are studied under the partially saturated conditions found in normal heat pipe operation. A vertical wick orientation, where the capillary lift is in opposition to gravity, is selected to test the wicks under the most demanding conditions. Mass transport measurements of the working fluid, in addition to the temperature field, are obtained for the porous wicks under the action of a discrete heat source (evaporator) mounted on one end. The working fluid, supplied from a condenser pool, evaporates from the wick surface primarily in the evaporator region, and is condensed and collected into a container separate from the pool, to yield mass flow rates. Thus the liquid-pumping capability of the wick, coupled with flow impedance, is measured as a function of applied heat flux. Repeatable results with low uncertainty are obtained. A careful analysis of the transport paths for heat and mass transfer in the wick structure confirms that mass transfer due to vaporization of the working fluid is the largest contributor to heat dissipation from the wick. The expected and measured values of evaporation rate are in good agreement. Results are also presented in terms of overall effective conductance based on measured temperatures.
\end{abstract}

\section{Nomenclature}

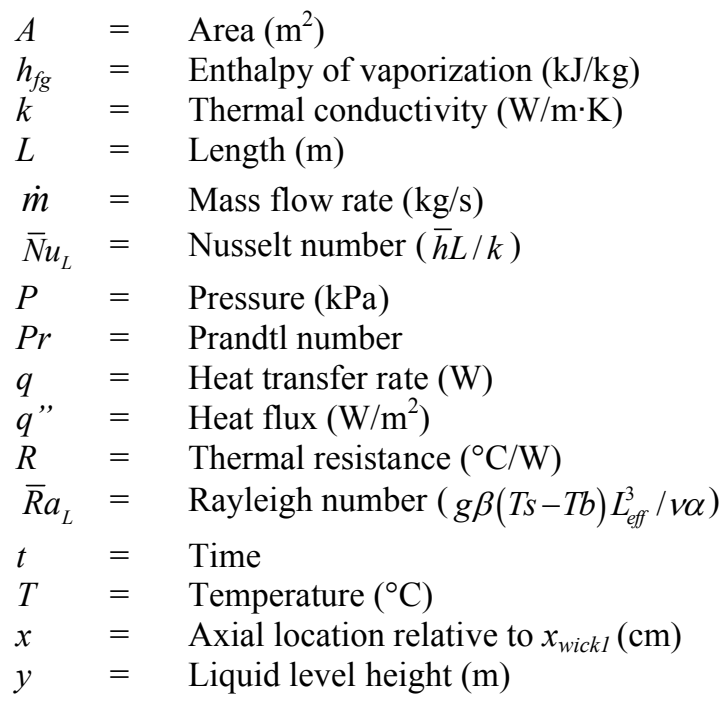

\footnotetext{
${ }^{*}$ To whom correspondence should be addressed: 765-494-5621; sureshg@purdue.edu
} 


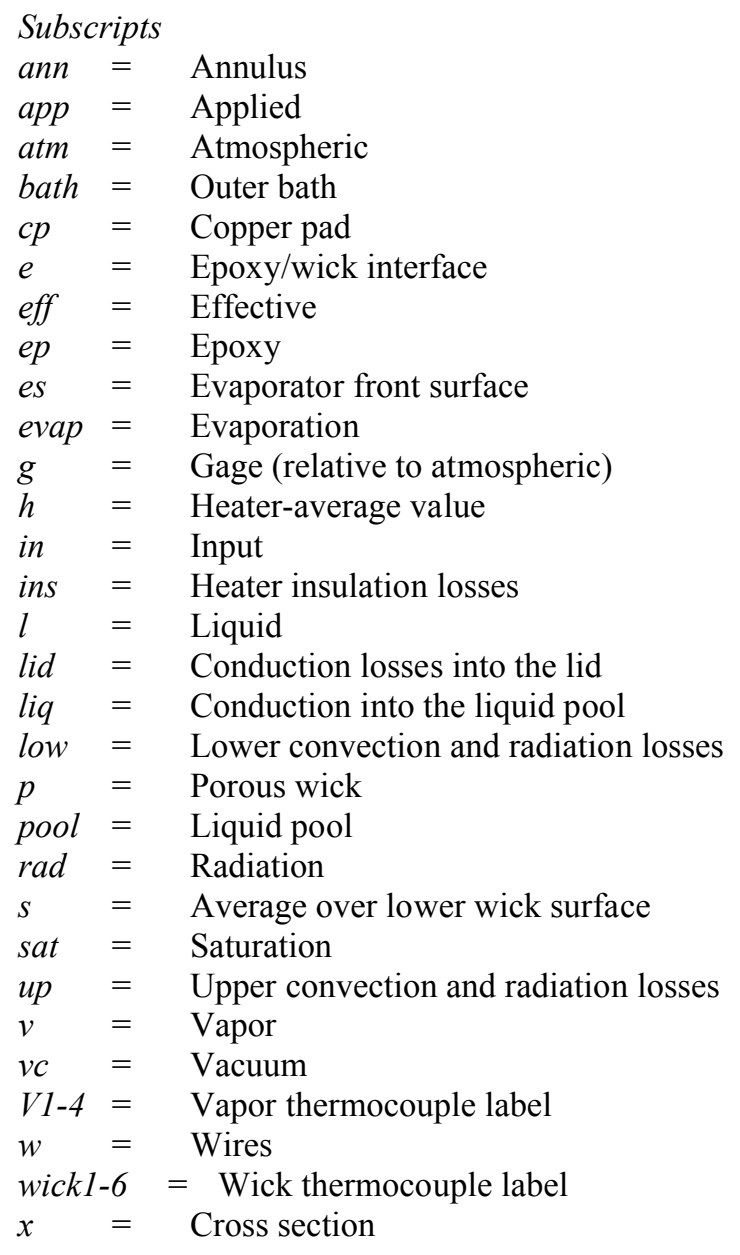

Greek Symbols

$\Delta=$ Change in quantity

$\varepsilon \quad=\quad$ Emissivity

$\rho \quad=\quad$ Density $\left(\mathrm{kg} / \mathrm{m}^{3}\right)$

$\sigma_{\mathrm{B}} \quad=$ Stefan-Boltzmann constant

\section{Introduction}

POrous media have long been studied in soil science and engineering. Flow through porous media has been studied with applications to a number of fields including food processing, heat exchangers, aerospace, and heat transfer. A fluid-filled porous structure provides solid-liquid-vapor contact lines in the interstitial volumes between the solid particles where large capillary forces can be developed from interfacial tensions. Liquid can be drawn through porous media as a result of these capillary forces. Heat pipes are one example in which passive fluid flow in porous media is exploited. The electronics cooling industry has employed heat pipes as a method of transferring 
heat over reasonable distances with relatively small changes in temperature since no external power source is required to drive the fluid flow.

A critical consideration in avoiding dryout and overheating in heat pipes is the ability of the wick structure to provide an adequate fluid supply to the evaporator. One source of pressure drop in heat pipes is the friction force caused by the solid matrix that slows fluid motion; this effect is quantified via the permeability. Commonly, the one-dimensional Darcy flow model is used for permeability analysis. However, heat pipe wicks under the action of an applied heat source also experience the added effects of evaporation which are not accounted for in Darcy's model. Regions of the wick near the heater may have dry or partially saturated voids. Since this approach assumes a fully saturated wick, it does not represent actual (unsaturated) wick operating conditions. Adkins and Dykhuizen ${ }^{1}$ discussed permeability measurement techniques and identified conditions under which the error between one- and two-dimensional analyses can be significant. Variants of this approach have been widely used by researchers and industry practitioners for permeability measurement. Vafai and $\operatorname{Tien}^{2}$ provided an error map for the applicability of Darcy's law when a boundary is present. Extensions of this work included boundary effects on mass transfer in porous media ${ }^{3}$ and numerical modeling of liquid flow that accounted for variable porosity. ${ }^{4}$ Various researchers have studied permeability for screen mesh wicks, ${ }^{5,6}$ felt metal wicks, ${ }^{7,8}$ and sintered porous media. ${ }^{9}$ Expressions for calculating permeability are also available in textbooks. ${ }^{10,11}$ Liquid flow studies in porous media have included anisotropic permeability, ${ }^{12}$ buoyancy induced flows, ${ }^{13}$ and dependence of flow properties on saturation. ${ }^{14}$ Visual observations of liquid flow including images of vapor formation have also been obtained. ${ }^{15,16}$

Porosity, which is the ratio of pore volume to total volume, is another parameter that affects liquid flow in porous media and can be determined from a variety of methods, with varying levels of accuracy. The simplest method is to compare the mass of a wick sample to the mass of a solid structure (with zero void volume) using known material densities. Adkins et al. ${ }^{1,7}$ used this method for characterizing wick porosity. Other methods, such as mercury intrusion ${ }^{9}$, and imbibition ${ }^{8}$ (suited for irregular geometries) have been employed to evaluate porosity. Additional porosity relations and tables can be found in heat pipe textbooks. ${ }^{10,11}$

A capillary radius has been used to characterize the average void volume by assigning a radius dimension to the void space. A commonly used method for obtaining the capillary radius in wick structures is termed the bubblepoint pore radius measurement. ${ }^{1}$ However, this method characterizes the pore radius using a single pore size that is determined from the largest pore flow path. This technique is rather inadequate for wick structure characterization 
since the maximum capillary pressure is defined by the minimum pore size. Regardless, it has been widely used in the literature due to its simplicity. ${ }^{1,7,8}$ Since actual wick structures include a range of capillary radii, non-wetting liquid intrusion methods have been employed to obtain distributions of capillary radius in porous structures. ${ }^{6}$ A third method of pore radius measurement, similar to the intrusion method, is liquid extrusion. ${ }^{17}$ This method includes 'through' pores (pores that contribute to the throughput of fluid) and not 'blind' pores (pores that do not accommodate flow in that direction) in the pore radius distribution. Pore radius can also be determined by measuring the rise in height of a liquid due to capillary action in a porous wick. In practice, this method often is difficult to repeat due to the difficulty in accurately distinguishing the liquid level height, but it can readily provide rough estimates and is still used. ${ }^{18,19}$

Porous wick structures carrying interstitial liquid can achieve high values of effective thermal conductivity due to the release of latent heat if the liquid can be made to evaporate. Since phase change occurs at a constant temperature, the temperature difference in Fourier's law of heat conduction is comparatively small for wick structures with evaporation. For a given amount of heat to be transferred over a given length, there must be a corresponding increase in the conductivity to accommodate the heat transport. In effect, the conductivity is increased by the inclusion of phase change. Commonly, this is referred to as an "effective thermal conductivity" $\left(k_{e f f}\right)$.

There have been numerous modeling efforts in the literature for effective thermal conductivity; experimentally obtained values have also been reported for various types of wicks. ${ }^{20-23}$ In the empirical approach, 1D conduction conditions are usually established and the temperature gradient across or along the wick structure is monitored. This information, coupled with the geometry and heat input, gives the conductivity according to Fourier's law. However, there remains much disparity among the results for effective thermal conductivity in the literature. For sintered copper wicks, a value of $40 \mathrm{~W} / \mathrm{m} \cdot \mathrm{K}$ has been generally used. ${ }^{24}$

Several studies aimed at characterizing the performance of heat pipes and their wick structures have been conducted. Some studies have illustrated the impact of properties on overall wick performance and have typically focused on determining dryout heat fluxes and the limits of operation for a given wicking mechanism. Garimella and Sobhan ${ }^{25}$ reviewed the state of the art in the understanding and analysis of a large variety of heat pipes, as well as their limitations. A comparison of maximum heat transfer rates for wrapped wire screen, square axial grooves and sintered metal powder wick was reported by Gupta and Upadhya. ${ }^{26}$ They showed that sintered metal powder 
wicks were found to be the most effective for both horizontal and adversely tilted heat pipes. Overall heat transfer capability in sintered porous media has been shown to be strongly affected by thin film evaporation. ${ }^{27}$ Further experimental studies of the wick dryout include work by Abhat and $\operatorname{Seban}^{28}$, Wang and Peterson ${ }^{29}$, among others. $^{23,30}$

Boiling in porous media has also been widely investigated. Shaubach et al. ${ }^{31}$ developed an analytical model for boiling in sintered metal wicks that included variation in wick properties, wick thermal conductivity as a function of the void fraction, evaporation at the liquid-vapor interface, and nucleate boiling within the wick. They addressed the problem of two-phase flow in evaporator sections of heat pipe wicks. Enhancement of boiling in wicks by introducing grooves in the evaporator was studied by Mughal and Plumb ${ }^{32}$ in an effort to reduce the resistance to vapor flow in evaporator sections. These are representative of the many studies regarding boiling in porous media in the literature, though many unanswered questions remain in this field.

The present work aims at obtaining mass flow rate measurements in heat pipe wick structures under conditions that simulate the operation of a heat pipe, and builds on the work initiated by Fields. ${ }^{33}$ A number of studies in the literature that have attempted such measurements are briefly discussed here, along with key differences from the present work. Chun ${ }^{30}$ studied the dryout limits of screen wicks oriented vertically in a topheating mode. Dryout heat fluxes were shown to be lower than would be expected from a fully saturated wick. This demonstrated the necessity of accounting for recession of the liquid-vapor evaporation boundary. A new wicking model based on such an approach was proposed. Permeability values and capillary radius were deduced from their estimation of maximum pumping capability at dryout. Recession of liquid into the wick was also demonstrated by Roberts and Feldman ${ }^{19}$, confirming that the wick is only partially saturated, thus reducing cross-sectional area available for liquid flow. When this partially saturated condition occurs, the thermal resistance can be considerably affected. They developed a theoretical model to predict heat pipe performance and confirmed their results using experiments on a cylindrical heat pipe with an annular wick wrapped on a mandrel and spot welded in place. However, a large variability in the wick properties (as much as $\pm 30 \%$ ) contributed to large uncertainties in their results.

Abhat and $\mathrm{Seban}^{28}$ conducted experiments to study evaporation from screen and felt wick structures. Effective conductivities were calculated for a gravity-opposing orientation. Maximum power inputs as a function of wall superheat were also obtained for varying liquid-pool depths at atmospheric pressure. However, neither axial 
temperature profiles nor mass flow rate results were obtained. They concluded that the observed increase in flow resistance was in part due to a liquid layer thinner than the wick thickness or by vapor flow resistance in holes connecting nucleation sites that originated at or near the tube surface.

Heat pipe operating limits for sintered wick structures were studied by Shibayama and Morooka. ${ }^{34}$ They investigated wick properties, friction losses and capillary properties, and measured maximum heat transfer rates. They aimed to include a wider range of experimental conditions than had been included in previous wick studies. Capillary pressure was determined using approximate liquid rise/fall tests and permeability quantified using Darcy's Law. Maximum heat transfer rates were determined from monitoring dryout as a sudden increase in temperature when the heat flux or the inclination angle was increased.

Imura et al. ${ }^{18}$ investigated heat transfer coefficients and maximum heat transfer rates for horizontal heat pipes with a stainless-steel screen wick. They emphasized the importance of accurate measurement of capillary radius, permeability and porosity in order to correctly predict maximum heat transfer rates and proposed an equation for determining porosity. Experiments were conducted in a vacuum environment and the effects of mesh size and number of screen layers on the maximum heat transfer rate were reported. Their work added support to the theory of recession of the liquid-vapor interface into the wick.

A novel experimental facility is developed in the present work, in which experimental measurements of mass flow rates in sintered copper wick samples are obtained in a vacuum environment, under conditions simulating the operation of a heat pipe. The results obtained shed light on wick performance over a range of heat flux levels. An important distinction between this work and previous studies is the inclusion of mass flow rate measurements of the evaporated fluid. Optical access in the novel apparatus developed allows such a measurement even under vacuum conditions. Since the evaporated fluid is condensed and collected for mass flow rate measurement, it is important that this experiment be conducted in an evacuated chamber so that the effects of noncondensable gases on the condensation process may be minimized. Knowledge of the mass flow rate allows wick characterization under unsaturated conditions unlike the typical saturated wick studies available.

The wick is oriented vertically in the experiments with heat applied at the top. Such an orientation characterizes the worst-case scenario for liquid flow and determines the feasibility of a wick for applications such as portable electronics. The present test facility can accommodate wicks of many different types. Desired rates of heat input 
can also be applied under tight control. The facility can also accommodate different working fluids, though only water has been considered in this study.

\section{Experimental Test Facility}

The apparatus and test procedures developed for testing wick structures are described. Key techniques used in preparation of the facility, test samples, and instrumentation of wicks are also provided.

\section{A. Apparatus Description}

The experimental apparatus is mainly comprised of an outer glass cylinder with an inner concentric cylinder forming an annulus (Figure 1). The apparatus design allows for a vertically suspended wick structure to lift working fluid, which for all cases considered in this paper is water, by capillary action from the inner liquid pool up to a heated region where the liquid is evaporated. The vapor then travels to condensing surfaces on the inner surface of the outer cylinder wall where heat is rejected to the surroundings and the vapor condenses. Condensate forming along the walls is then collected in the annulus (which is separated from the inner liquid pool).

The annulus, shaped to collect the condensate, does not extend the full length of the outer cylinder, and instead allows for an open vapor collection area near the top of the apparatus (as shown in Figure 1). The bottom of this annulus is sealed to the outer wall with silicone sealant, thereby separating the inner liquid pool from the collected condensate. A rigorous determination of the amount of fluid collected was ensured using a mass-based and a volume-based approach to determine the average cross-sectional area of the annulus. In the mass-based approach, the weight and height of added water in the annulus were measured. Using the density of water, the cross-sectional area was calculated. In the volume-based approach, the volume and height of added water were measured and then divided to obtain the cross-sectional area. These two methods provided results that were within $1 \%$ of each other. The average cross-sectional area determined by these two methods was used for the calculation of condensate volume. The outer cylinder is capped with an aluminum lid which seals the vapor chamber with an O-ring as shown

in Figure 1. The aluminum cap is equipped with additional components necessary for pressure regulation, data retrieval and wick mounting.

Two 'pass-throughs' integrated into the aluminum lid allow the thermocouple and heater lead wires to be connected to the data acquisition system and power source, respectively. The pass-throughs were custom-fabricated in-house to accommodate the required number of thermocouple lines and heater wiring in the limited lid space 
available. On the underside (interior) of the aluminum lid, a clamp was fashioned in order to grip the wick during experimentation (Figure 2). The clamping mechanism consists of two high density polyethylene (HDPE) blocks that are held together by two cap screws. In order to reduce heat loss from the wick into the clamp, a layer of rubber was included between the wick and the insulating clamp blocks.

To simulate the evaporator region of a heat pipe, a flexible Kapton thin-film heater was attached to a solid copper pad $(0.5 \mathrm{~cm}$ thick) with a thermally conducting epoxy (Epoxies Etc. $50-3100 \mathrm{resin}, k=2.16 \mathrm{~W} / \mathrm{m} \cdot \mathrm{K}$ ) as in Figure 3. This copper pad was then mounted on the wick structure, again using the same thermally conductive epoxy. Holes were drilled to the center of the copper pad to place thermocouples for monitoring temperature in the heating region. The heaters used for the tests reported in this work were $1.9 \mathrm{~cm} \times 1.9 \mathrm{~cm}$ in area. An HDPE insulation block was attached behind the heater on the side opposite the wick to minimize heat loss.

Thermocouples were mounted along the back of the wick to monitor the axial temperature profile. Schematic diagrams with dimensions and thermocouple labels for unbacked and backed wicks are included in Figure $2 \mathrm{a}$ and $\mathrm{b}$, respectively. Two evenly spaced thermocouples were placed in the copper pad adjacent to the heater and six additional thermocouples were evenly spaced along the remaining exposed wick length. All thermocouples were made of T-type 36-gage wire, and attached with thermally conducting epoxy. A number of additional thermocouples were included in the apparatus as illustrated in Figure 4. These temperature measurements track the working fluid as it evaporates and then condenses. A schematic representation of the change in vapor temperature from the evaporator to condenser sections, as introduced by Mills ${ }^{35}$, is also shown in this figure. Mills suggested that the largest gradient in vapor temperature occurs near the condenser. It will be shown from the experimental results that a similar trend of change in vapor temperature is observed with the current facility.

A cap with a conical top surface was placed to cover the inner cylinder from which working fluid is drawn from the liquid pool (Figure 1). A slot was cut in this cap to allow wick access to the liquid pool; the slot is just larger than the wick, and there is no contact between the wick and the cap. The function of this cap is to minimize the flow of evaporated fluid to the liquid pool surface, since it is desired that the vapor condense on the outer wall and collect in the annulus. The conical relief allows liquid condensed on the cap to run into the condensate collection area.

Water in the liquid pool and annulus is changed between each test to ensure fluid cleanliness. The entire apparatus is placed in a large water-filled tank (not shown in Figure 1) at room temperature, providing a constanttemperature condition on the exterior of the facility. 


\section{B. Wick Samples}

The porous wick structures investigated in this work are sintered copper samples fabricated from sieved copper particles. Since the porous structures are free-standing, and not mounted on a solid wall, the wicks needed to be fairly thick in order to ensure structural integrity. The copper powder was sieved at Thermacore, Inc., using standard NIST screens yielding grain size ranges as listed in Table 1. The backed samples consisted of a thinner sintered copper powder layer with similar pores sizes bonded to a solid copper wall backing. A selected particle range of copper grains were then sintered together in a mold. Deformation and volume reduction during sintering occurs at different rates for different particle sizes yielding a slightly dissimilar cross section for each sample (see also Table 1). After sintering, the wicks were heated in a hydrogen-rich reducing atmosphere to approximately 600 ${ }^{\circ} \mathrm{C}$. Any oxide present on the wick surfaces was thus reduced. Organic contaminants (such as oil from handling) were also cleaned in the high-temperature process.

In order to avoid contamination that can affect the wetting properties of the pores after cleaning, the samples were sealed in bags in an inert gas atmosphere to avoid oxidation. During instrumentation and handling, gloves were always worn to prevent oils and dirt from transferring to the wick. While the wicks were open to atmosphere during epoxy cure, open wicks were always stored in the evacuated wick chamber between tests for protection from contamination and exposure to oxygen in the atmosphere. While some oxidation on the surfaces was unavoidable, the duration of exposure was limited to the period of preparation time between test runs.

While sintered copper powder samples with water as the working fluid are investigated in this work, the facility can accommodate virtually any wick structure or fluid, and the analysis methodology is valid across many wick types.

\section{Data Acquisition}

Thermocouples in the test apparatus are read by a data acquisition system which records the information through the duration of a test. Figure 5 illustrates the increase in heater temperature through a typical test cycle. Each test run at a specified power setting was allowed to reach a steady state with power adjustments being made within the first 20 minutes of the test. For a constant power input, it is apparent that the heater temperatures are still climbing slightly even at the end of the testing interval. For the test case illustrated in the figure, the heater temperatures increase on average by $0.6{ }^{\circ} \mathrm{C}$ every 20 minutes during the $60-120$ minute interval. This is likely due to the continuous increase in temperature of the liquid pool since its temperature is not strictly held constant as heat is 
applied. Other temperature measurements in the vapor and on the wick exhibit similar slight increases in temperature during the nominal steady state (though less pronounced increases are observed on the wick). Steadystate measurements are obtained by averaging measurements over a 40-minute interval, generally between 80-120 minutes into the test.

The evaporation rate of the working fluid is determined by collecting the condensate as outlined in the apparatus description above. As the condensed fluid runs into the condensate collection annulus, the water level rises over time. Incremental readings of the water level at specific times during a test provide the mass flow rate according to

$$
\dot{m}=\rho A_{a n n} \Delta y / \Delta t
$$

where $\rho$ is the fluid density (997 kg/m $\mathrm{m}^{3}$ for water), $\Delta y$ the fluid height change and $\Delta t$ the corresponding time between height measurements. The area $\left(A_{a n n}\right)$ of the annulus was carefully determined in advance as previously described. During operation, liquid level heights were recorded through the duration of the test. Sufficient time was allowed for fluid to collect in order to make measurements over larger, more distinguishable changes in volume. The rate of evaporation is then determined from the measured mass flow rate according to

$$
q_{\text {evap }}=\dot{m} h_{f g}
$$

in which $h_{f g}$ for water is $2450 \mathrm{~kJ} / \mathrm{kg}$.

The power dissipated in the thin film heater is also monitored using the data acquisition system. The power dissipated in the resistance heater was determined from the measured output voltage of the power supply and the current (determined using the measured voltage drop across a $0.01 \Omega$ shunt resistor). Resistance in the wiring to the heaters also contributes to power loss in the wires $\left(q_{w}\right)$. The sum of the lead wire resistances $\left(R_{w}\right)$ from the power supply to the apparatus lid and from the apparatus lid to the thin film heater is $0.493 \Omega$; with this information, the voltage drop in the lead wires is computed.

\section{Heat and Mass Transfer Paths}

In order to calculate the expected rate of evaporation, the following heat and mass transport paths were considered, as illustrated in Figure 6. Conduction loss from the wick through the clamping mechanism to the lid is termed $q_{\text {lid. }}$. Heat loss through the heater insulation is $q_{\text {ins }}$. Convection and radiation losses along the length of the wick are separated into an upper and a lower region (as indicated in Figure 6) and labeled $q_{u p}$ and $q_{l o w}$, respectively. Evaporation of working fluid along the length of the wick is $q_{\text {evap }}$ and conduction down the wick into the liquid pool 
is $q_{\text {lig. }}$. Transport along each path was quantified using first principles, or by additional testing procedures, as outlined below.

The sum of $q_{l i d}, q_{u p}$ and $q_{\text {ins }}$ was determined empirically by isolating their effects from the other modes of transport. A short length of porous wick, which is not in contact with the liquid pool, was tested (Figure 3a). In this configuration, illustrated in Figure $6 \mathrm{~b}, q_{l i d}, q_{u p}$ and $q_{\text {ins }}$ are quantified. A series of tests at different power levels were conducted for this configuration, and the average steady-state heater temperature recorded at each power level. A relationship between input power and heater temperature was then obtained as a curve-fit to the results:

$$
q_{\text {in,loss }}=0.038 T_{h}-0.912 \text {. }
$$

A good estimate of the sum of $q_{l i d}, q_{u p}$ and $q_{\text {ins }}$ could thus be obtained for each normal wick test (as in Figure 6a) by substituting the measured average heater temperature into the curve-fit relationship. Negligible convection in the chamber and limited contribution from radiation result in a linear dependence of heat loss on temperature. No discernible difference was noted for this component of heat transfer between wicks of both pore sizes for the unbacked wicks considered in this study.

Convection and radiation losses along the lower region of the wick $\left(q_{\text {low }}\right)$ were estimated by using established heat transfer correlations for free convection from a vertical plate and radiation from a small surface to large surroundings. Free convection from the lower face was calculated using the commonly used correlation by Churchill and Chu valid for $R a_{L} \leq 10^{9}$ :

$$
\bar{N} u_{L}=0.68+\frac{0.670 R a_{L}{ }^{1 / 4}}{\left[1+(0.492 / \mathrm{Pr})^{9 / 16}\right]^{4 / 9}} .
$$

The driving temperature difference for calculation of $R a_{L}$ was based on the average face temperature in the lower region and the constant outer bath temperature, while $L$ is the exposed length of the wick between the heater and the liquid pool. The gas properties used in the calculation are evaluated using the chamber pressure. The radiation loss in the lower wick region was determined from

$$
q_{\text {rad }}=\varepsilon A_{\text {low }} \sigma_{B}\left(T_{s}^{4}-T_{b a t h}^{4}\right)
$$

where $T_{s}$ is the average wick surface temperature in the region of the lower surface area $\left(A_{\text {low }}\right), T_{\text {bath }}$ is the outer bath temperature, and emissivity $(\varepsilon)$ is selected to be unity. The sum of convection and radiation losses defined in this manner constitutes $q_{\text {low }}$. 
Heat conduction down the length of the wick into the liquid pool $\left(q_{\text {liq }}\right)$ is determined from the temperature gradient in the wick near the surface of the liquid pool according to

$$
q_{\text {liq }}=k A_{x}\left(\frac{T_{\text {wick } 2}-T_{\text {wick } 1}}{x_{\text {wick } 2}-x_{\text {wick } 1}}\right)
$$

where the last two thermocouples at the bottom near the liquid pool surface (wick1 and wick2, Figure 2) are used for the temperature gradient calculation and $k$ is assumed to be $40 \mathrm{~W} / \mathrm{m} \cdot \mathrm{K} .{ }^{24}$ Since the conductivity through the porous layer is not explicitly determined, the assumed conductivity value for all wick samples at all applied power settings is one source of uncertainty in this loss mode calculation. However, since $q_{\text {liq }}$ is a very small fraction of the applied heat, the effect of this uncertainty on the overall result is minimal.

Summing the estimates for each of the transport modes outlined above and subtracting them from the applied power, the last remaining unknown, $q_{\text {evap }}$, can be obtained. In this manner, an expected value for the evaporation rate is determined in this work. While vapor may be formed along the length of the wick structure, the majority of the evaporation for wicks in this study is expected to occur in the evaporator region. This assumption is supported by the fact that temperatures greater than the saturation temperature are only observed well above the conical cap.

The electrical power applied to the heater $\left(q_{a p p}\right)$ is corrected for losses as follows, to obtain the corrected power input $\left(q_{i n}\right)$ to the wick system:

$$
q_{i n}=q_{a p p}-\left(q_{w}+q_{l i d}+q_{u p}+q_{i n s}\right)=q_{a p p}-\left(q_{w}+q_{\text {in,loss }}\right)
$$

The heat transferred by radiation and convection from the wick $\left(q_{u p}\right)$ would normally not be considered losses, but are included since the sum of the last three terms on the right side of the equation is empirically determined as a whole in this work; this is a minor correction, however, with $q_{u p} / q_{a p p}$ being always less than $5 \%$.

\section{E. Operating Pressure and Temperature}

Condensation rates can be adversely affected by the presence of noncondensible gases as these gases present a barrier to vapor condensation. A ball valve and pipe fittings through the aluminum lid provide access for a vacuum pump to remove noncondensible gases prior to testing. The vacuum pump is attached to a two-way valve, and once evacuation is complete, the valve connection to the surroundings is closed and the pump disconnected. The vacuum setup allows the absolute pressure in the chamber to be reduced to values on the order of $5.1 \mathrm{kPa}(1.5 \mathrm{inHg}) \mathrm{prior}$ to test initiation. Vacuum leakage has been verified to be less than $0.85 \mathrm{kPa}(0.25 \mathrm{inHg})$ during the time interval of a 
test ( 2 hours). A vacuum pressure gage mounted on the aluminum lid provides the relative pressure between atmospheric and chamber pressures. Absolute vacuum pressure $\left(P_{v c}\right)$ is determined by the difference between gage and atmospheric pressures and is comprised of the partial pressures due to noncondensibles and the vapor. Atmospheric pressure is also recorded during steady-state operation. Using the gage pressure at the beginning of the test, the extent of noncondensible gases are quantified. Using the gage pressure at steady state, the saturation conditions of the liquid are determined. These pressure values are recorded in Table 2 for wicks TCR1 and TCR5, and in Table 3 for wicks BACK2, BACK3, and BACK4. While this is not a direct measure of the partial pressure of noncondensable gases, it does provide the total internal pressure at which a saturation temperature can be estimated. There is a slight increase in saturation temperature with input power using this approach resulting from a larger contribution of the vapor partial pressure at higher power levels.

\section{F. Uncertainty Analysis}

An uncertainty analysis was performed on the measured and expected evaporation rates. The uncertainties in the measured evaporation rate principally result from the least count uncertainty in measurement of the liquid level in the collection annulus. Therefore there is a nearly constant level of uncertainty for the measured evaporation rate of about $1.46 \mathrm{~W}$. This results in measured evaporation rate uncertainties ranging from approximately $17 \%$ for low input powers to $2 \%$ for higher input powers. Uncertainties in the expected values were estimated through an analysis performed on each of the quantities used in calculating the expected $q_{\text {evap }}$ and range from approximately $14 \%$ for low input powers to $4 \%$ for higher input powers. It will be seen that the measured and expected evaporation rate error bars overlap for all test results.

\section{Results and Discussion}

Results from experiments performed on wicks TCR1 and TCR5 (Table 1) are presented in terms of heat and mass transport capability as a function of input heat flux. Tests were performed on the wicks at increasing power increments of $10 \mathrm{~W}$ until the heating mechanism was compromised or dryout was observed. Heat flux levels of up to $20 \mathrm{~W} / \mathrm{cm}^{2}$ were sustained by wicks TCR1 and TCR5 without dryout. For higher power levels, the heater insulation began warping and pulling away from the heater, affecting its ability to insulate the back side of the heater. When this occurred, the power level was no longer increased further and the test was concluded. As a result, the highest input power for each wick was different. The backed wicks sustained similar heat flux levels, and thus, 
their smaller cross-sectional area was shown to be adequate to transport the required mass flow rate of liquid at these power input levels.

\section{A. Wick Temperature}

Axial wick temperatures and chamber vapor temperatures along with input power and chamber pressure data are listed in Table 2. Comparison of the average heater temperature in the copper pad $\left(T_{h}\right)$ to the calculated saturation temperature $\left(T_{\text {sat }}\right)$ reveals a large difference that increases with input power (see Table 2). A simple 1D conduction analysis as shown in Figure 7 reveals that there is a significant jump in temperature across the epoxy $(\mathrm{k}=2.16$ $\mathrm{W} / \mathrm{m} \cdot \mathrm{K}$ ) used to attach the copper pad to the wick structure. The heat source assembly temperature is thus an inadequate representation of the wick back surface temperature, as illustrated in Figure 8. For example, at the 52.8 W power input for TCR1, the heater temperature is $74.2^{\circ} \mathrm{C}$. Using the $1 \mathrm{D}$ conduction analysis in Figure 7 , the temperature at the epoxy/wick interface is only $49.3^{\circ} \mathrm{C}$ for an epoxy thickness of approximately $0.35 \mathrm{~mm}$. The interface temperature is thus much closer to the saturation temperature $\left(38.2^{\circ} \mathrm{C}\right)$ and front face vapor temperature $\left(41.3^{\circ} \mathrm{C}\right)$ for this test case. Similar temperature reductions across the heat source assembly and epoxy are observed for the 17.2 W case also shown in Figure 8. The average heater temperature $\left(T_{h}\right)$ is therefore distinguished from the epoxy/wick interface temperature that may be assumed to be the evaporator temperature $\left(T_{e}\right)$. Although some uncertainty is involved in evaluating the evaporator temperature from the 1D resistance network calculation, this temperature is used in all temperature profile plots that follow (indicated by the dotted line segments), as it more closely represents the surface temperature along the back of the wick. As shown in Table 3, the addition of evaporator surface thermocouples for the backed wicks allowed a direct measurement of the evaporation temperature, which was found to be very close to both the calculated saturation temperature and the measured vapor temperature.

The axial temperature profiles along wicks TCR1 and TCR5 are plotted in Figure 9. The last two data points on the far right in each curve of these figures correspond to the estimated evaporator temperature $\left(T_{e}\right)$. The remaining six are equally spaced along the wick (Figure 2). Axial thermocouple locations are referenced to the location of wick1, i.e., wick 1 corresponds to an axial position of 0 in the temperature profiles of Figure 9. At the beginning of a test run, the liquid pool level reaches a height near the second wick thermocouple and the fluid level decreases as the fluid is pumped through the porous structure and is measured as condensate on the outer walls. For high heat fluxes, as the end of the test approaches, this fluid level drops below the last wick thermocouple such that it no longer is 
submerged in the liquid pool. Varying levels of liquid pool height are encountered, depending on input power. The effect of this small variation in liquid pool level on the temperature profile would be relatively minor since the difference in temperatures recorded by the lower thermocouples (wick 1-3) is of the same order as the uncertainty in the measurement $\left( \pm 1^{\circ} \mathrm{C}\right)$.

A number of trends can be inferred from Figure 9. As expected, there is a general increase in axial temperatures at higher applied heat fluxes. It is also observed that the temperature difference across thermocouples wick1 to wick6 is quite small, on the order of $10^{\circ} \mathrm{C}$ at even the highest applied heat fluxes. The temperature difference along a solid copper sample of the same dimensions as TCR1 at a power input of $\sim 60 \mathrm{~W}$ would have a temperature difference on the order of $60^{\circ} \mathrm{C}$. The benefits of energy absorption into latent heat of vaporization are clear from this comparison. The vaporization of working fluid at a constant temperature limits the increase in temperature along the wick until dryout has been reached.

The temperature of the heat source assembly increases linearly with input power, as do the wick temperatures. It is interesting to note that near the evaporator region, the gradient for TCR1 appears to flatten (for an input power of $69.8 \mathrm{~W}$ ), perhaps indicating that the temperature in this region is suppressed due to possible boiling. Also, the larger temperature drop along the wick (from $T_{\text {wick } 6}$ to $T_{\text {wickl }}$ ) for this case may be due to a partially unsaturated wick in which an increasing fraction of heat is transported down the length of the wick by conduction and a decreasing fraction to evaporation.

Six separate tests were performed on wick TCR1 to verify repeatability, three each at two different adjusted input power levels of $17 \mathrm{~W}$ and $44 \mathrm{~W}$. All wick temperature measurements were found repeatable to within $2^{\circ} \mathrm{C}$ and heater temperature measurements were repeatable within a slightly larger range of $3^{\circ} \mathrm{C}$.

The corresponding axial temperature trends for the backed wick BACK2 are shown in Figure 10a. The steeper temperature gradient from the liquid pool to the evaporator in this case is attributed to the addition of the solid copper backing and the overall reduction in cross section.

\section{B. Evaporation Rate}

Collected vapor condensate in the condensate collection annulus (Figure 1) yields the mass flow rate measurements on the liquid mass being lifted and evaporated during wick operation. This measured value is compared to an expected evaporation rate based on the heat and mass transport analysis provided in description of 
the test facility above. Figure 11 shows a comparison of the measured and expected evaporation rates for TCR1 and TCR5.

A linear increase in evaporation rate is seen with an increase in applied input power as expected. Quantification of the other possible heat transport modes reveals that approximately $80-85 \%$ of the unadjusted applied power is transferred to the working fluid by evaporation. In Figure 11, it is clear that, in fact, most of the applied input power is manifest as the evaporation rate. Thus the dominant transport mode in these wicks is the capillary pumping power

and its ability to provide the necessary fluid for evaporation before dryout occurs. Nearly the same measured mass flow rate is observed for both TCR1 and TCR5; these two wicks show good agreement over the 10 62 W range with slightly increased deviation at the last comparable power setting. For these levels of power input and wick cross section, the capillary forces in both wick structures provide the required pressure head to overcome gravity and viscous forces that oppose the liquid flow.

Comparison of the expected to measured evaporation rates demonstrates the robustness of the measurement technique developed. These two values agree to within $13 \%$ for all cases, and generally are within $8 \%$. The repeatability in the measurement of evaporation rate (with the same six tests for wick TCR1 as for the wick temperature measurements discussed above) is within the uncertainty of the measurement method. For the three tests at an adjusted input power of $17 \mathrm{~W}$, the standard deviation is $0.83 \mathrm{~W}$, which is only about $5 \%$ of the input power. Similarly, for the three tests at $44 \mathrm{~W}$, the standard deviation is $1.10 \mathrm{~W}$, only $3 \%$ of the input power.

Figure $10 \mathrm{~b}$ shows the measured and expected evaporation rates for wick BACK2 for a range of input power levels. Of particular importance is the ability of the backed wicks to remove comparable heat flux levels without dryout even though the porous layer is much thinner than the unbacked case. The same method of heat and mass transfer paths is used here, again showing good agreement with relatively low uncertainty.

\section{Vapor Temperature}

As illustrated in Figure 4, the transition from vapor temperature at the location of evaporation to the condenser liquid temperature occurs rather abruptly ${ }^{35}$; axial conduction along a wick tends to widen the distance over which a transition in vapor temperature occurs. Similar vapor temperature maps, constructed from thermocouple measurements at locations shown in Figure 4, are illustrated for TCR1 and TCR5 in Figure 12 (a) and (b), respectively. It is noted that the $\mathrm{x}$-axis location of each temperature measurement is approximate in these figures. However, it is their position relative to each other along the evaporator-to-condenser path that is important. 
It is clear in these plots that a transition, similar to that represented in Figure 4 from evaporator vapor temperature to condenser liquid temperature, is observed at the different power levels for the two wicks. Temperatures are plotted relative to the outer bath temperature since this is ultimately the temperature of heat removal from the apparatus and provides the cooling along the walls for condensation to occur. Comparison of the vapor temperatures between the two wicks reveals similar temperatures at similar power settings. For example, at an input power of $52 \mathrm{~W}$, the vapor temperature immediately in front of the wick face $\left(\mathrm{T}_{\mathrm{V} 1}\right.$ of Figure 4$)$ was $41.3{ }^{\circ} \mathrm{C}$ and $40.0^{\circ} \mathrm{C}$ for wicks TCR1 and TCR5, respectively. More scatter is apparent in vapor temperature measurements over that of surface-mounted thermocouples, since the former thermocouples were repositioned for each test run with some resulting variability in location.

There is some vapor superheat in the region in front of the wick structure for larger input powers. This superheat increases with increasing input power and a corresponding shift is observed away from the heater of the location at which saturation temperature is obtained (see highlighted temperatures in Table 2). At these higher input powers, the region of the wick over which vaporization occurs also increases.

\section{Thermal Conductivity}

Although there are many ways to evaluate heat pipe wick conductivity based on different temperatures and length scales, one representative approach is presented here. It is emphasized that the conductivity addressed below is not an instrinsic property of the wick structure, but rather a means of demonstrating the conductivity enhancement. Additional fundamental studies are being conducted to evaluate wick conductivity by isolating this phenomenon. ${ }^{36}$

In the present work, overall heat pipe conductivity is based on the temperature difference at the surface of the "heat pipe" from the evaporator to the condenser as illustrated in Figure 13. Although the heat and mass transfer is not truly one-dimensional in the wick testing configuration, an effective conductivity based on the cross-sectional area of the wick structure can be calculated from the total temperature difference along the wick $\left(T_{e}-T_{p o o l}\right)$ according to

$$
k_{\text {eff }}=\frac{q_{\text {in }} L_{e f f}}{A_{x}\left(T_{e}-T_{p o o l}\right)}
$$

where $L_{\text {eff }}$ is the length from the midpoint of the evaporator region to the location of thermocouple wick1 (see Figure 2). This conductivity characterizes the combined action of conduction through the wick structure and the 
evaporation. It may be noted that this calculation differs from that for a heat pipe in that a heat pipe would have additional contributions to the cross-sectional area from the wall and vapor core, which are not included for the wick here. Changes in conductivity with input power for wicks TCR1 and TCR5 are shown in Figure 14a.

It is observed in Figure 14a that conductivity values increase with input power for wicks TCR1 and TCR5, for the lower power inputs. This increase in conductivity results from a larger portion of the applied energy going into latent heat of vaporization. This can be best illustrated by examining the amount of heat conducted down the length of a wick into the liquid pool during operation as shown in Figure 15. Heat transfer by conduction into the liquid pool has been normalized by the sum of heat transfer due to conduction into the liquid pool and due to evaporation. This figure demonstrates that as input power increases, a smaller fraction of the input power is conducted down the length of the wick. The energy not being conducted into the liquid pool goes towards vaporization. This translates into increased effectiveness of the heat pipe with increasing power.

The conductivity begins to taper off at power levels of approximately $40 \mathrm{~W}$ for both wicks. At these higher power levels, not only is the estimated epoxy/wick interface temperature $\left(T_{e}\right)$ above the saturation temperature (at $P_{v c}$ ) but $T_{\text {wick }}$ also has a temperature above saturation; it is possible that boiling may have commenced in the wick structure. A further increase in heat flux causes the temperature in the evaporator to increase beyond saturation. As the evaporator excess temperature increases, the location on the wick where the temperature is equal to the saturation value shifts down the wick as in Table 2. This is also corroborated by the crossover in temperature profiles in Figure 9a at the higher heat fluxes. If indeed these data indicate boiling, then it is possible that dryout does not occur immediately upon the initiation of boiling and results in a sustained boiling condition. Eventually, the conductivity would appear to drop off with further increases in heat flux since the evaporation rate deteriorates as the extent of boiling increases. Effective resistance values $\left(R_{\text {eff }}=q_{i n} /\left(T_{e}-T_{p o o l}\right)\right.$, inverse of effective conductivity $)$ along the wick decrease with increasing input power until excess temperature in the evaporator region has increased and the resistance levels off. Resistance magnitudes for the $30-60 \mathrm{~W}$ range are on the order of $0.5{ }^{\circ} \mathrm{C} / \mathrm{W}$, attractive for electronics cooling.

The enhancement in effective thermal conductivity of a wick structure due to evaporation can be quantified based on a comparison against the conductivity of solid copper $(\sim 400 \mathrm{~W} / \mathrm{m} \cdot \mathrm{K})$. At the larger power inputs included in Figure 14a, these wick structures have conductivity values that are three times that of a solid copper blank of 
similar dimensions. However, if the temperature difference used in the conductivity measurement were changed from $T_{e}-T_{p o o l}$ to $T_{V 1}-T_{p o o l}$, the resulting conductivity magnitude can be 2 or 3 times greater.

Figure $14 \mathrm{~b}$ shows a similar effective conductivity analysis for backed wicks BACK2, BACK3, and BACK4. The effective conductivity for all backed wicks is shown to increase linearly for all power levels tested, and is nearly double in magnitude relative to the unbacked wicks. However, a direct comparison between backed and unbacked wicks is difficult due to the difference in their cross-sectional areas.

\section{Conclusions}

A novel experimental facility has been developed to simulate testing conditions that more accurately replicate the conditions experienced by wicks during heat pipe operation. Under such conditions, wick performance, including evaporation rates, has been experimentally quantified for sintered copper powder wicks of varying porosity. Measurement results of the heat and mass transport modes reveal that the largest contributor to heat dissipation is the energy that is transferred into latent heat of vaporization. As input power is increased and more heat is dissipated by the wick, a relatively larger amount of this heat is dissipated by vaporizing the working fluid and a correspondingly smaller value is conducted axially along the solid matrix resulting in increased effectiveness.

Measured axial temperature and evaporation rates indicate that the two wicks tested performed similarly even though they have different grain geometry. Both sintered copper powder wick structures performed well even in a vertical orientation. The wicks did not experience dryout for heat fluxes up to approximately $20 \mathrm{~W} / \mathrm{cm}^{2}$. Conductivity values roughly three times as high as copper were observed in both of the wicks investigated.

For lower power levels, at which conductivity increased with input power, the evaporator remained at a temperature near or below saturation. For higher power levels, the excess temperature in the evaporator increased, resulting in possible boiling initiation. The wick did not experience dryout immediately at this boiling initiation but sustained boiling for the moderate excess temperatures in this work.

The experimental method and analysis was repeated for wicks with similar pore sizes bonded onto a solid copper wall that more closely mimic commercial heat pipe wicks. Using the same heat and mass transfer path analysis, the backed wicks were shown to remove the same heat flux levels as the unbacked wicks with twice the effective conductivity. 


\section{Acknowledgment}

The authors acknowledge financial support for this work from members of the Cooling Technologies Research Center (www.ecn.purdue.edu/CTRC), a National Science Foundation Industry/University Cooperative Research Center at Purdue University.

\section{References}

1 Adkins, D.R. and Dykhuizen, R.C., "Procedures for Measuring the Properties of Heat-Pipe Wick Materials," 28th Intersociety Energy Conversion Engineering Conference, Vol. 2, Atlanta, GA, 1993, pp. 911-917.

${ }^{2}$ Vafai, K. and Tien, C.L., "Boundary and Inertia Effects on Flow and Heat Transfer in Porous Media," International Journal of Heat and Mass Transfer, Vol. 24, No. 2, 1981, pp. 195-203.

${ }^{3}$ Vafai, K. and Tien, C.L., "Boundary and Inertia Effects on Convective Mass Transfer in Porous Media," International Journal of Heat and Mass Transfer, Vol. 25, No. 8, 1982, pp. 1183-1190.

${ }^{4}$ Vafai, K., Alkire, R.L., and Tien, C.L., "An Experimental Investigation of Heat Transfer in Variable Porosity Media," Journal of Heat Transfer, Vol. 107, No. 3, 1985, pp. 642-647.

${ }^{5}$ Noda, H., Yoshioka, K., and Hamatake, T., "Experimental Study on the Permeability of Screen Wicks," JSME International Journal, Series B: Fluids and Thermal Engineering, Vol. 36, No. 2, 1993, pp. 357-363.

${ }^{6}$ Adkins, D.R. and Moss, T., "Measuring Flow Properties of Wicks for Heat Pipe Solar Receivers," $12^{\text {th }}$ Annual International Solar Energy Conference, Miami, FL, 1990, pp. 103-108.

${ }^{7}$ Adkins, D.R., Moss, T.A., Andraka, C.E., Andreas, N.H., and Cole, H.M., "Examination of Metal Felt Wicks for Heat-Pipe Applications," Proceedings of the 1995 ASME/JSME/JSES International Solar Energy Conference, Vol. 1, ASME, Maui, HI, 1995, pp. 553-558.

${ }^{8}$ Williams, R.R. and Harris, D.K., "Cross-Plane and in Plane Porous Properties Measurements of Thin Metal Felts:

Applications in Heat Pipes," Experimental Thermal and Fluid Science, Vol. 27, No. 3, 2003, pp. 227-235.

${ }^{9}$ Guyon, E., Oger, L., and Plona, T.J., "Transport Properties in Sintered Porous Media Composed of Two Particle Sizes," Journal of Physics D: Applied Physics, Vol. 20, No. 12, 1987, pp. 1637-1644.

${ }^{10}$ Chi, S.W., Heat Pipe Theory and Practice, Hemisphere Publishing Corporation, New York, 1976.

${ }^{11}$ Faghri, A., Heat Pipe Science and Technology, Taylor and Francis, 1995.

${ }^{12}$ Qin, W. and Liu, C.Y., "Liquid Flow in the Anisotropic Wick Structure of a Flat Plate Heat Pipe Under Block-Heating Condition," Applied Thermal Engineering, Vol. 17, No. 4, 1997, pp. 339-349.

${ }^{13}$ Zhao, T.S., Liao, Q., and Cheng, P., "Variations of Buoyancy-Induced Mass Flux from Single-Phase to Two-Phase Flow in a Vertical Porous Tube with Constant Heat Flux," Journal of Heat Transfer, Vol. 121, No. 3, 1999, pp. 646-652.

${ }^{14}$ Ambrose, J.H., Chow, L.C., and Beam, J.E., "Detailed Model for Transient Liquid Flow in Heat Pipe Wicks," Journal of Thermophysics and Heat Transfer, Vol. 5, No. 4, 1991, pp. 532-538.

${ }^{15}$ McCreery, G.E., "Liquid Flow and Vapor Formation Phenomena in a Flat Heat Pipe," Heat Transfer Engineering, Vol. 15, No. 4, 1994, pp. 33-41.

${ }^{16}$ Fang, C., Peng, X.F., and Yang, Z., "Visualization of Liquid-Vapor Two-Phase Flow in Porous Media," 6th International Symposium on Heat Transfer, Beijing, China, 2004, pp. 424-429.

${ }^{17}$ Jena, A. and Gupta, K., "A Novel Mercury Free Technique for Determination of Pore Volume, Pore Size and Liquid Permeability Principle," 2002, URL: http://www.pmiapp.com/publications/index.html [cited 31 March 2005].

${ }^{18}$ Imura, H., Kozai, H., Hayashida, S., and Takashima, K., "Heat-Transfer Characteristics in Screen-Wick Heat Pipes," JSME International Journal, Series 2, Vol. 31, No. 1, 1988, pp. 88-97.

${ }^{19}$ Roberts, C.C. and Feldman, K.T.J., "Predicting Performance of Heat Pipes with Partially Saturated Wicks," Rubber World, 1972, pp. 2-11.

${ }^{20}$ Abo El-Nasr, A. and El-Haggar, S.M., "Effective Thermal Conductivity of Heat Pipes," Heat and Mass Transfer, Vol. 32, No. 1-2, 1996, pp. 97-101.

${ }^{21}$ Bauer, T.H., "General Analytical Approach Toward the Thermal Conductivity of Porous Media," International Journal of Heat and Mass Transfer, Vol. 36, No. 17, 1993, pp. 4181-4191.

${ }^{22}$ Buonanno, G. and Carotenuto, A., "Effective Thermal Conductivity of a Porous Medium with Interconnected Particles," International Journal of Heat and Mass Transfer, Vol. 40, No. 2, 1997, pp. 393-405.

${ }^{23}$ Udell, K.S., "Heat Transfer in Porous Media Considering Phase Change and Capillarity - the Heat Pipe Effect," International Journal of Heat and Mass Transfer, Vol. 28, No. 2, 1985, pp. 485-495.

${ }^{24}$ Grubb, K., "CFD Modeling of a Therma-Base (TM) Heat Sink," 8th International FLOWTHERM User Conference, Las Vegas, NV, 1999, URL: http://www.flomerics.com/flotherm/technical papers/t235.pdf [cited 18 April 2006]. 
${ }^{25}$ Garimella, S.V. and Sobhan, C.B., "Recent Advances in the Modeling and Applications of Nonconventional Heat Pipes," Advances in Heat Transfer, Vol. 35, 2001, pp. 249-308.

${ }^{26}$ Gupta, A. and Upadhya, G., "Optimization of Heat Pipe Wick Structures for Low Wattage Electronics Cooling Applications," Advances in Electronic Packaging 1999, Pacific RIM/ASME International Intersociety Electronics Photonic Packaging Conference, Vol. 26, Maui, HI, 1999, pp. 2129-2137.

${ }^{27}$ Hanlon, M.A. and Ma, H.B., "Evaporation Heat Transfer in Sintered Porous Media," Journal of Heat Transfer, Vol. 125, No. 4, 2003, pp. 644-652.

${ }^{28}$ Abhat, A. and Seban, R.A., "Boiling and Evaporation from Heat Pipe Wicks with Water and Acetone," Journal of Heat Transfer, Vol. 96, No. 3, 1974, pp. 331-337.

${ }^{29}$ Wang, Y.X. and Peterson, G.P., "Analytical Model for Capillary Evaporation Limitation in Thin Porous Layers," Journal of Thermophysics and Heat Transfer, Vol. 17, No. 2, 2003, pp. 145-149.

${ }^{30}$ Chun, K.R., "Some Experiments on Screen Wick Dry-Out Limits," Journal of Heat Transfer, Vol. 94, 1972, pp. 46-51.

${ }^{31}$ Shaubach, R.M., Dussinger, P.M., and Bogart, J.E., "Boiling in Heat Pipe Evaporator Wick Structures," $7^{\text {th }}$ International Heat Pipe Conference, Minsk, Belarus, 1990, pp. 1-15.

${ }^{32}$ Mughal, M.P. and Plumb, O.A., "Experimental Study of Boiling on a Wicked Surface," International Journal of Heat and Mass Transfer, Vol. 39, No. 4, 1996, pp. 771-777.

${ }^{33}$ Fields, R.E., "An Experimental Characterization of Heat and Mass Transport in Flat Heat Pipes," Master's Thesis, School of Mechanical Engineering, Purdue University, 2002.

${ }^{34}$ Shibayama, S. and Morooka, S., "Study on Heat Pipe," International Journal of Heat and Mass Transfer, Vol. 23, No. 7, 1980, pp. 1003-1014.

${ }^{35}$ Mills, A.F., Heat and Mass Transfer, Irwin, Chicago, 1995.

${ }^{36}$ Davis, T.W., "Experimental Characterization of the Transport Properties of Heat Pipe Wicks," Master's Thesis, School of Mechanical Engineering, Purdue University, 2006. 


\section{List of Tables}

Table 1 Wick TCR1 and TCR5 properties and geometry.

Table 2 Pressure and temperature data indicating increasing excess temperature in the evaporator for wicks TCR1 and TCR5.

Table 3 Pressure and temperature data indicating close agreement between face temperature and vapor temperature for wick BACK2, BACK3, and BACK4.

\section{List of Figures}

Figure 1 Schematic of wick testing apparatus. The entire test apparatus is immersed in a constant temperature water bath maintained at room temperature.

Figure 2 Overall wick schematic including wick clamping, heater insulation, thermocouple labeling and dimensions (in $\mathrm{cm}$ ) for (a) unbacked wicks TCR1 and TCR5 and, (b) backed wicks BACK2, BACK3, and BACK4.

Figure 3 Wick (a) heater assembly, (b) dimension orientation, and (c) thermocouple instrumentation.

Figure 4 Schematic diagram of (a) thermocouple placement for vapor tracking and test chamber condition monitoring, and (b) transition of vapor temperature from evaporator to condenser.

Figure 5 Temperature increase for wick TCR1 through steady state at a nominal power input of $50 \mathrm{~W}$ (not adjusted for losses).

Figure 6 Heat and mass transport modes for (a) actual wick test, and (b) loss test to estimate $q_{l i d}, q_{i n s}$ and $q_{u p}$.

Figure 7 1D resistance network for heat flow from heat source assembly into the wick structure (not to scale).

Figure 8 Wick evaporator region temperature adjustment in two representative tests for wick TCR1.

Figure 9 Temperature profiles for wicks (a) TCR1 and (b) TCR5 at various applied power settings.

Figure 10 (a) Temperature profiles, and (b) measured and expected evaporation rates for wick BACK2.

Figure 11 Measured and expected evaporation rates for wicks (a) TCR1 and (b) TCR5 at various input power levels.

Figure 12 Vapor temperature map for (a) wick TCR1 and (b) TCR5 from wick front to condensate pool. Saturation temperatures $\left(T_{\text {sat }}-T_{\text {bath }}\right)$ vary from approximately 9 to $17{ }^{\circ} \mathrm{C}$ for wick TCR 1 and 11 to $15{ }^{\circ} \mathrm{C}$ for wick TCR5 as in Table 2.

Figure 13 Criterion for calculation of overall effective wick conductivity $\left(k_{e f f}\right)$.

Figure 14 Overall effective conductivities for (a) TCR1 and TCR5, and (b) BACK2, BACK3 and BACK4 at various input power levels.

Figure 15 Normalized conduction rate into the liquid pool for TCR1 and TCR5 as a function of input power. 
Table 1 Wick TCR1 and TCR5 properties and geometry.

\begin{tabular}{|c|c|c|c|c|c|}
\hline Wick Name & TCR1 & TCR5 & BACK2 & BACK3 & BACK4 \\
\hline NIST Screen Size & $-45+60$ & $-200+325$ & $-60+100$ & $-100+140$ & $-140+200$ \\
\hline ASTM Sieve Opening ( $\mu \mathrm{m})$ & $355-250$ & $75-45$ & $250-150$ & $150-106$ & $106-75$ \\
\hline Average Pore Radius ${ }^{1}$ - Volume $(\mu \mathrm{m})$ & 17.06 & 18.1 & - & - & - \\
\hline Median Pore Radius ${ }^{2}$ - Surface $(\mu \mathrm{m})$ & 12.99 & 15.62 & - & - & - \\
\hline Median Pore Radius ${ }^{1}$ - Volume $(\mu \mathrm{m})$ & 27.68 & 15.62 & - & - & - \\
\hline Sample Width (cm) & 2.37 & 2.17 & 2.50 & 2.50 & 2.50 \\
\hline Sample Depth (cm) & 0.597 & 0.554 & 0.089 & 0.089 & 0.089 \\
\hline Cross Sectional Area $\left(\mathrm{cm}^{2}\right)$ & 1.42 & 1.20 & 0.22 & 0.22 & 0.22 \\
\hline Porosity $^{3}$ & 0.60 & 0.46 & 0.56 & 0.53 & 0.52 \\
\hline
\end{tabular}

Table 2 Pressure and temperature data indicating increasing excess temperature in the evaporator for wicks TCR1 and TCR5.

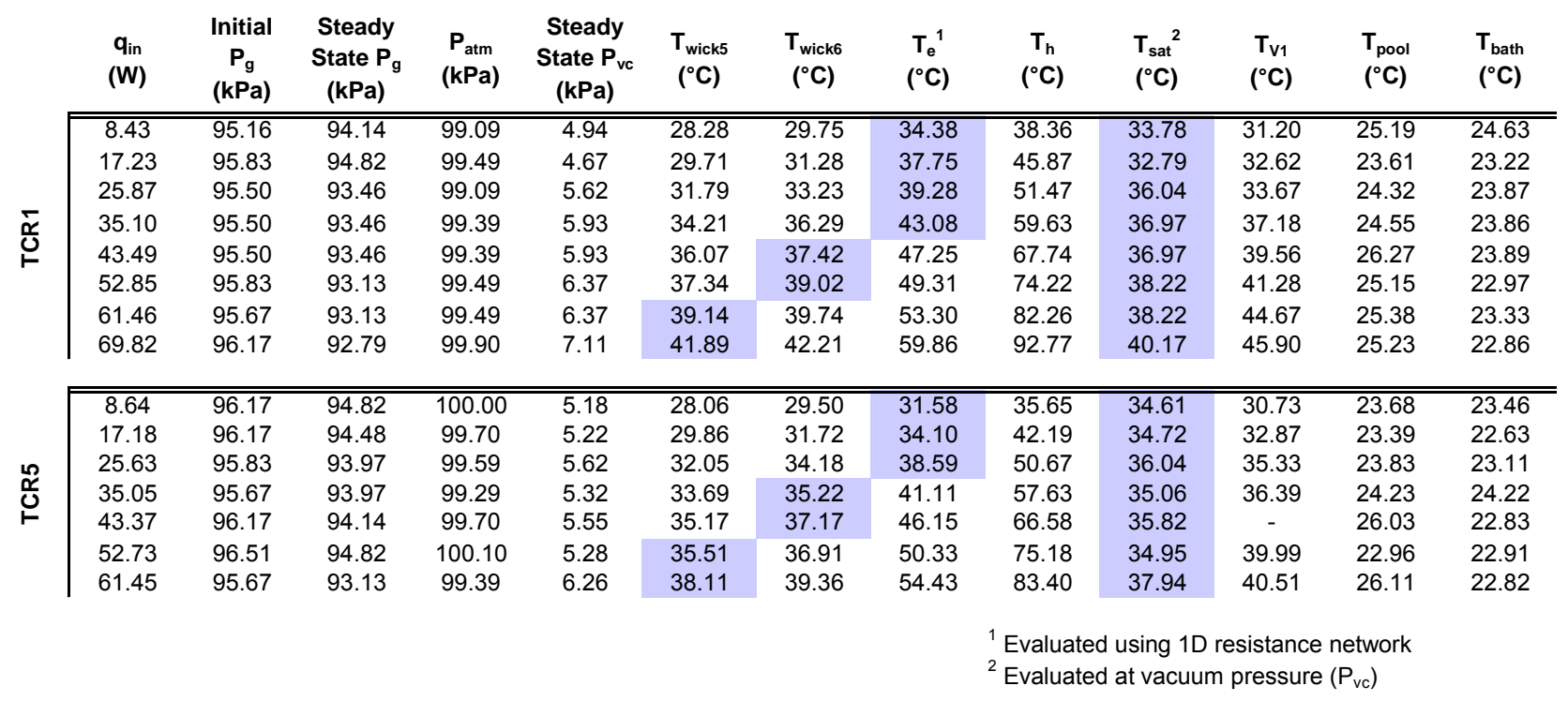


Table 3 Pressure and temperature data indicating close agreement between face temperature and vapor temperature for wick BACK2, BACK3, and BACK4.

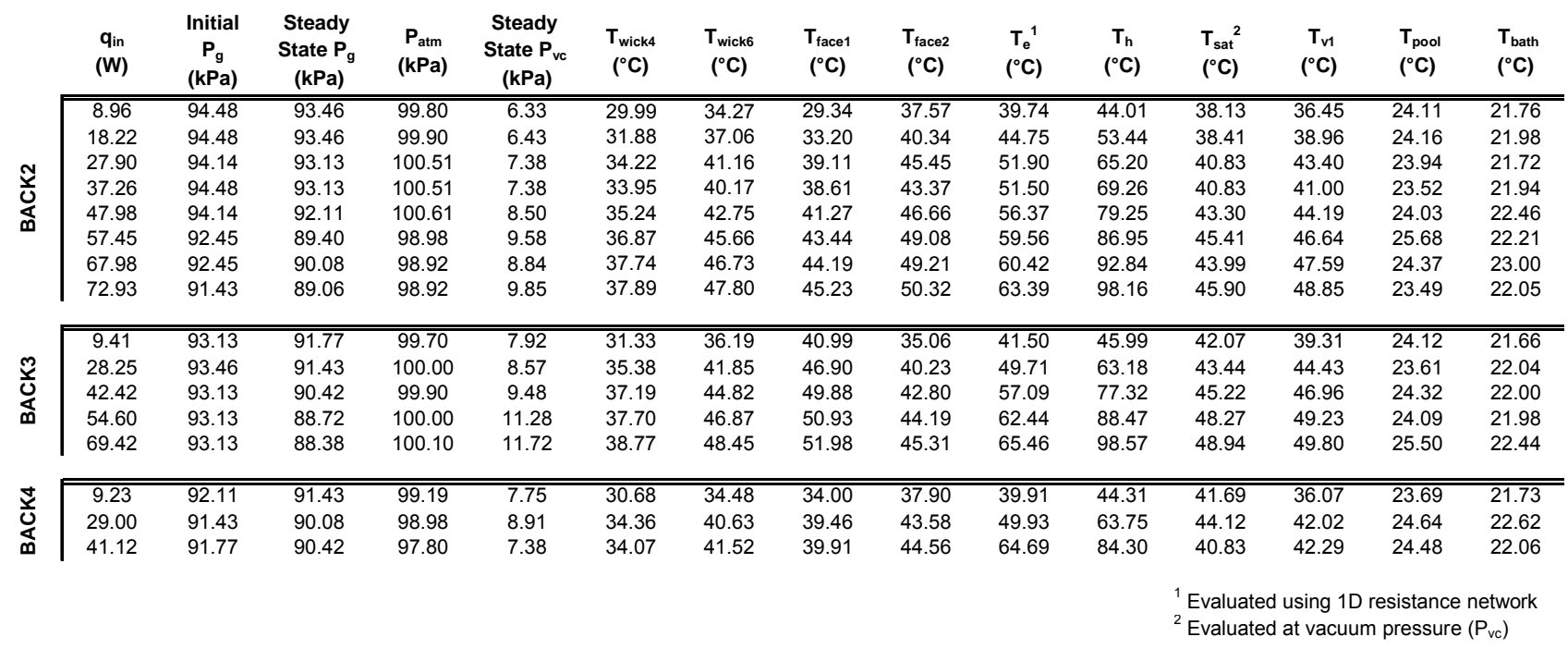




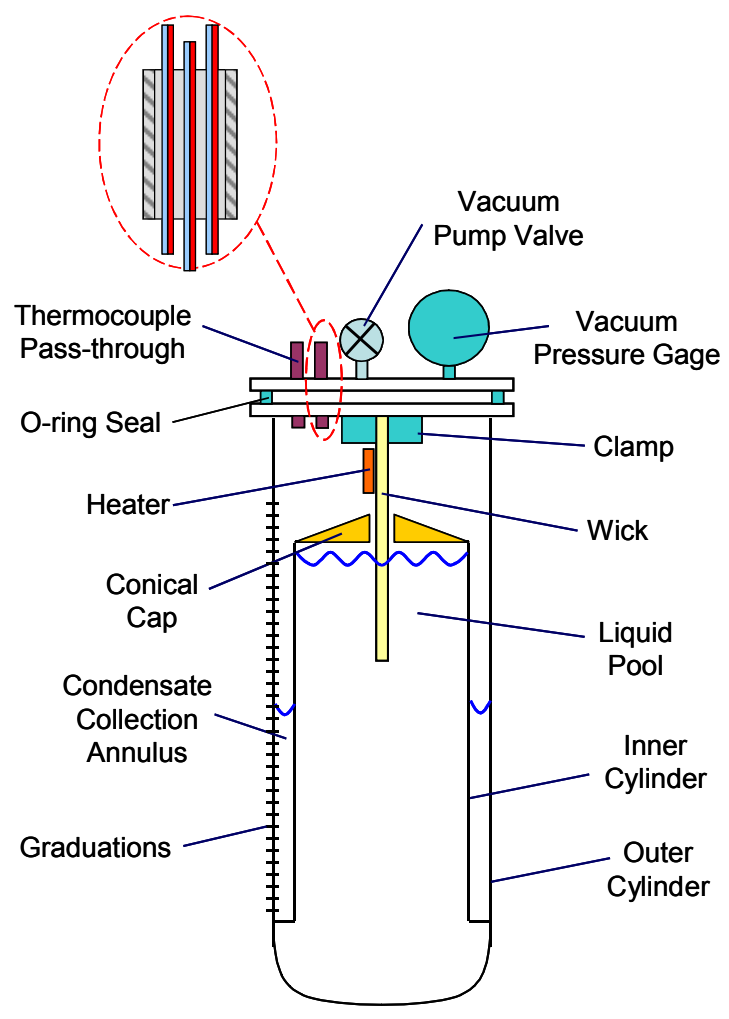

Figure 1 Schematic of wick testing apparatus. The entire test apparatus is immersed in a constant temperature water bath maintained at room temperature. 


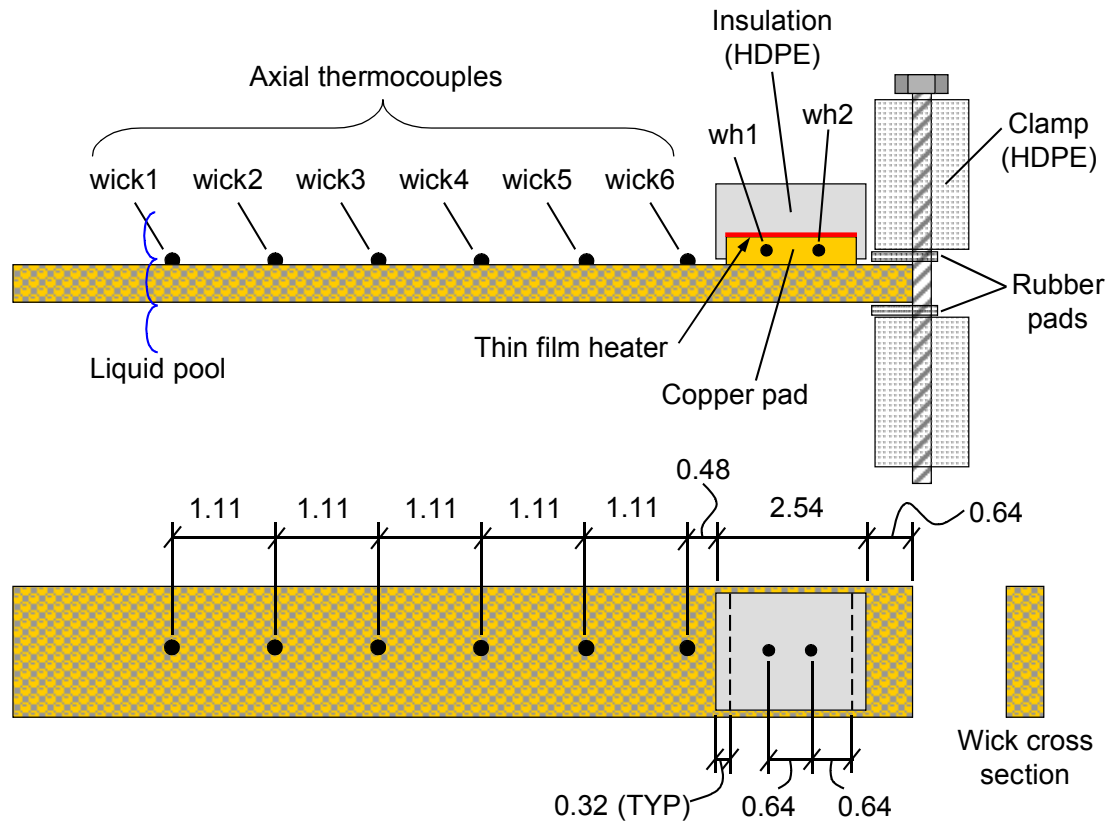

(a)
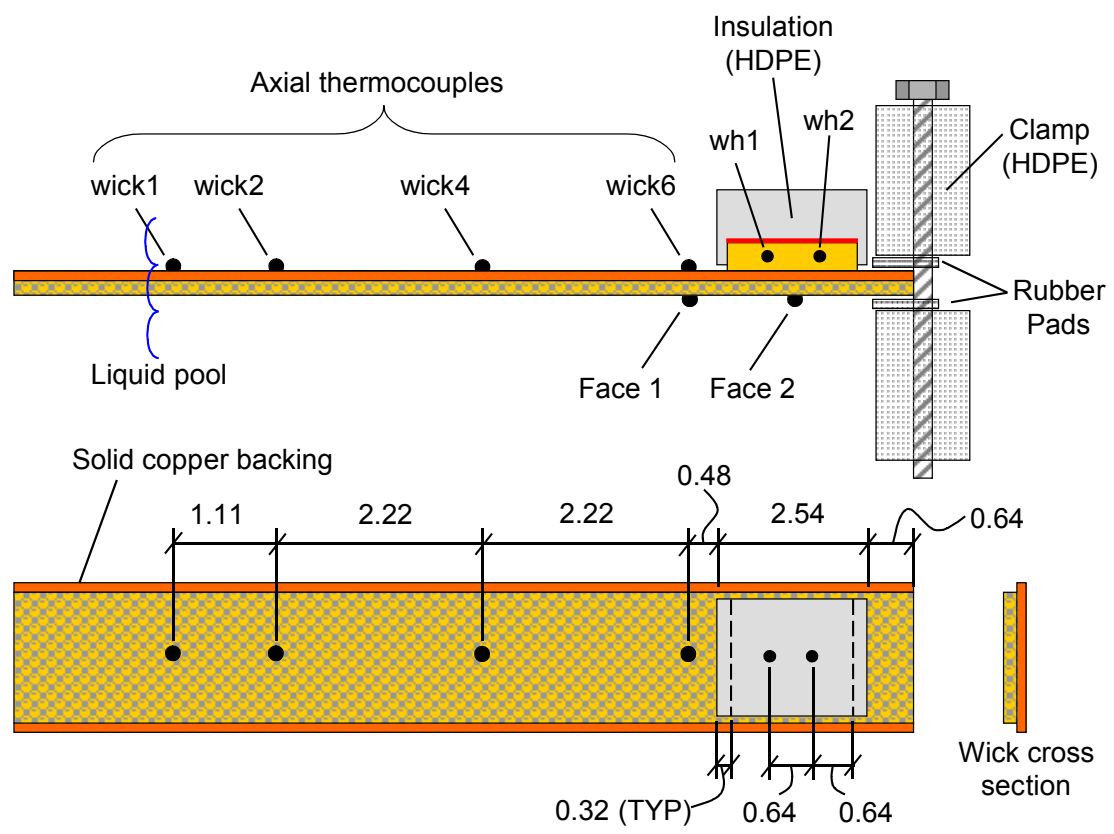

(b)

Figure 2 Overall wick schematic including wick clamping, heater insulation, thermocouple labeling and dimensions (in cm) for (a) unbacked wicks TCR1 and TCR5 and, (b) backed wicks BACK2, BACK3, and BACK4. 


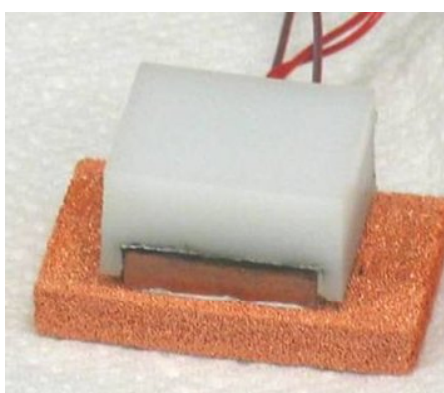

(a)

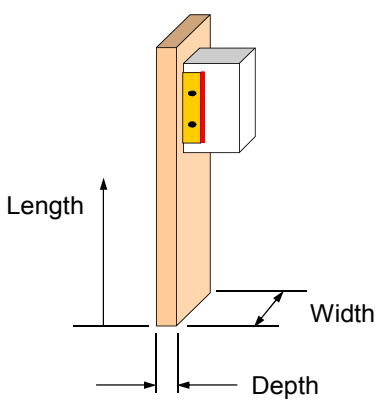

(b)

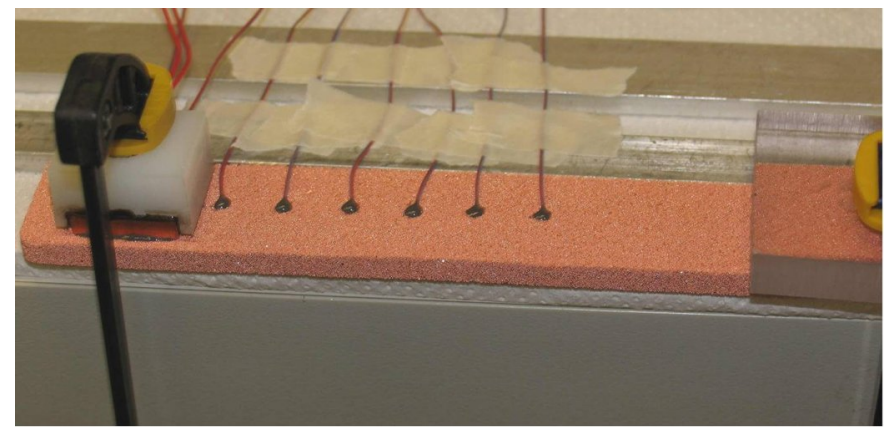

(c)

Figure 3 Wick (a) heater assembly, (b) dimension orientation, and (c) thermocouple instrumentation. 


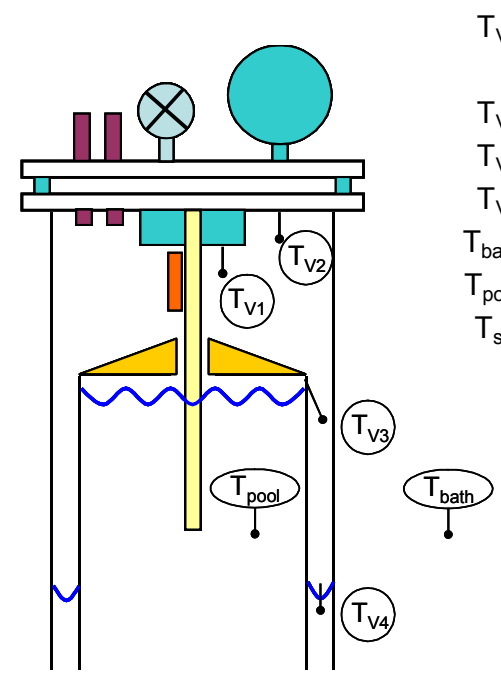

(a)
$\mathrm{T}_{\mathrm{V} 1}=$ Vapor temperature in front of wick face in evaporator region

$\mathrm{T}_{\mathrm{V} 2}=$ Bulk vapor temperature

$\mathrm{T}_{\mathrm{V} 3}=$ Vapor temperature near condensation surface

$\mathrm{T}_{\mathrm{V} 4}=$ Condensed liquid temperature

$\mathrm{T}_{\text {bath }}=$ Outer bath temperature

$\mathrm{T}_{\text {pool }}=$ Liquid pool temperature

$\mathrm{T}_{\text {sat }}=$ Saturation temperature at vacuum pressure

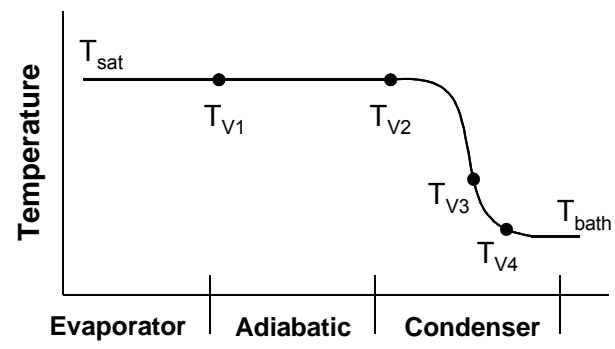

(b)

Figure 4 Schematic diagram of (a) thermocouple placement for vapor tracking and test chamber condition monitoring, and (b) transition of vapor temperature from evaporator to condenser. 


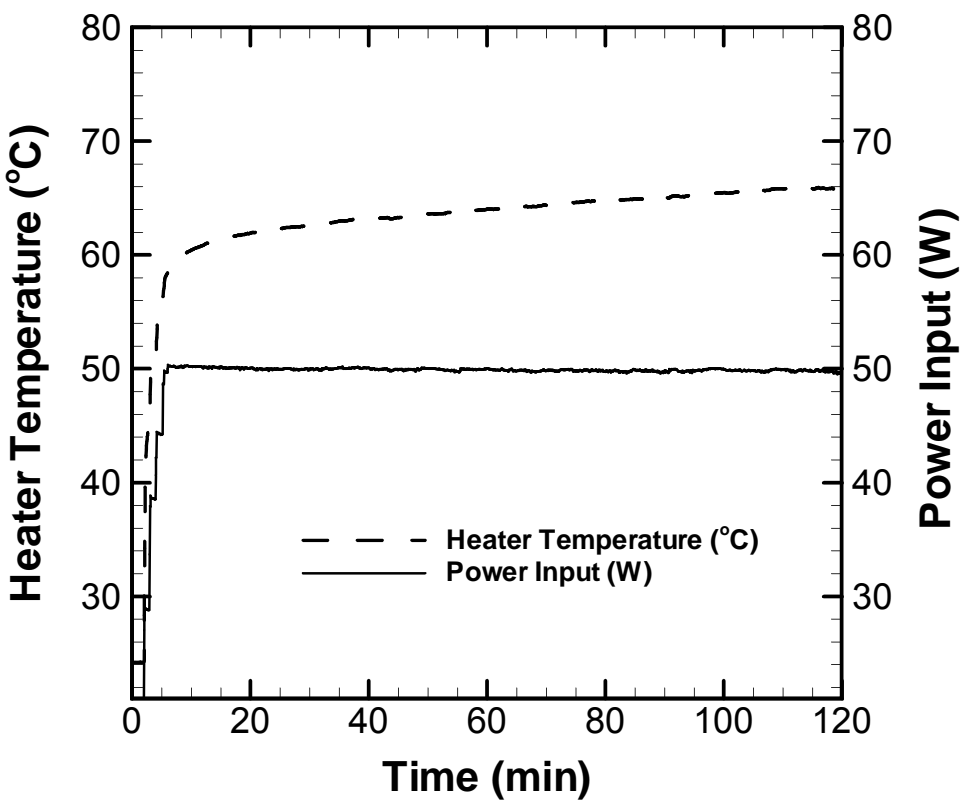

Figure 5 Temperature increase for wick TCR1 through steady state at a nominal power input of $50 \mathrm{~W}$ (not adjusted for losses). 


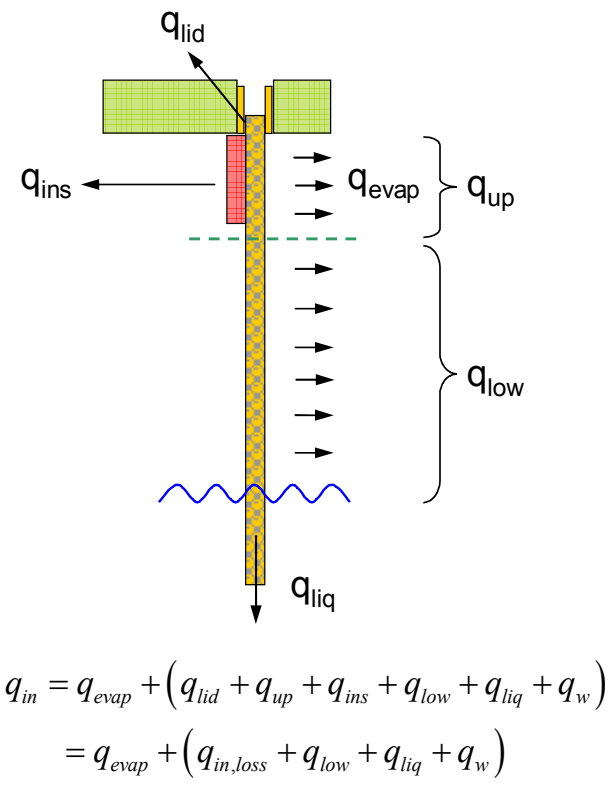

(a)

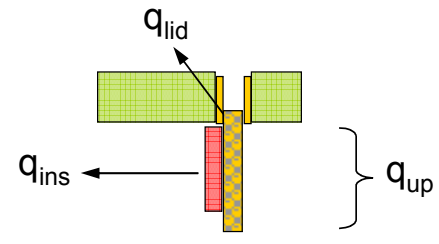

$q_{\text {in,loss }}=\left(q_{\text {lid }}+q_{\text {ins }}+q_{\text {up }}\right)_{\text {losses }}$

(b)

Figure 6 Heat and mass transport modes for (a) actual wick test, and (b) loss test to estimate $q_{l i d}, q_{i n s}$ and $q_{u p}$. 


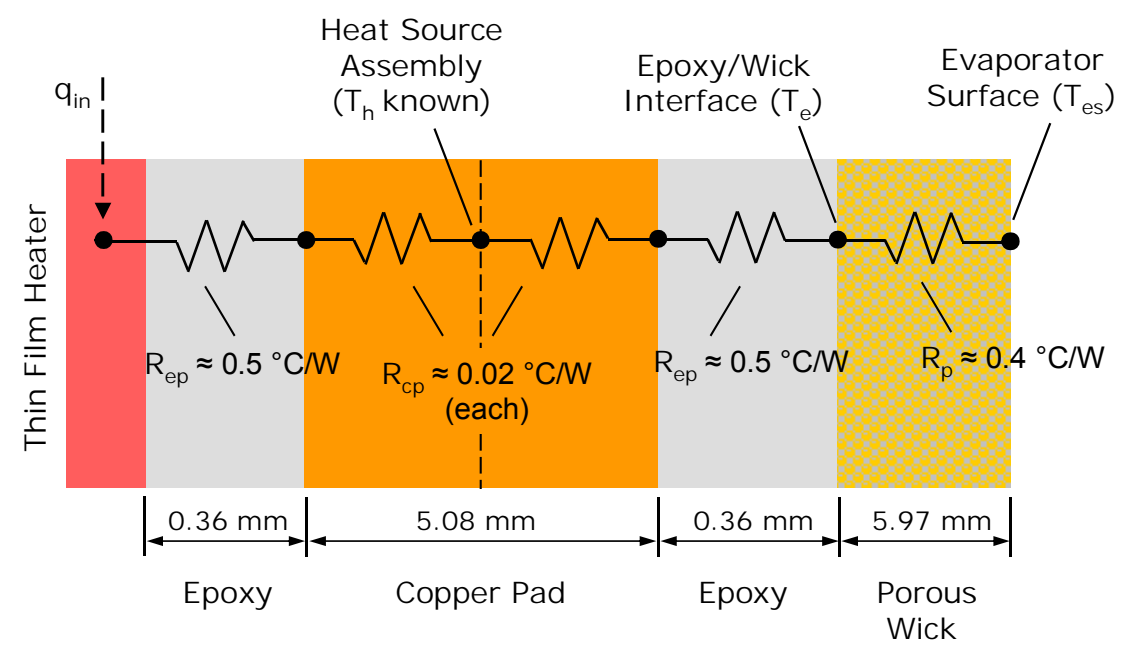

Figure 7 1D resistance network for heat flow from heat source assembly into the wick structure (not to scale). 


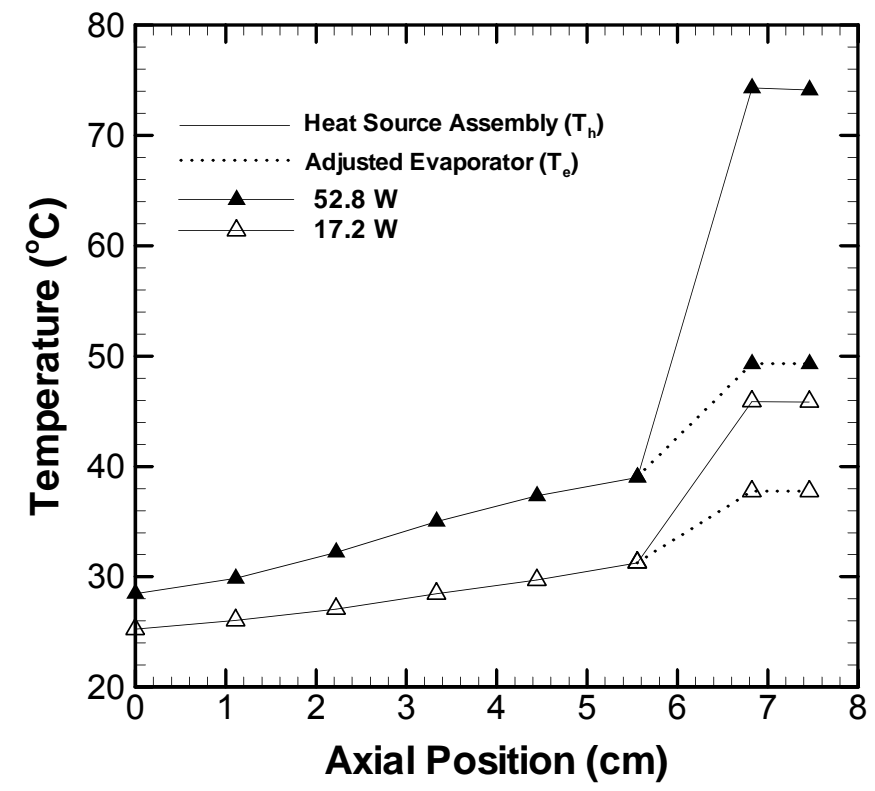

Figure 8 Wick evaporator region temperature adjustment in two representative tests for wick TCR1. 


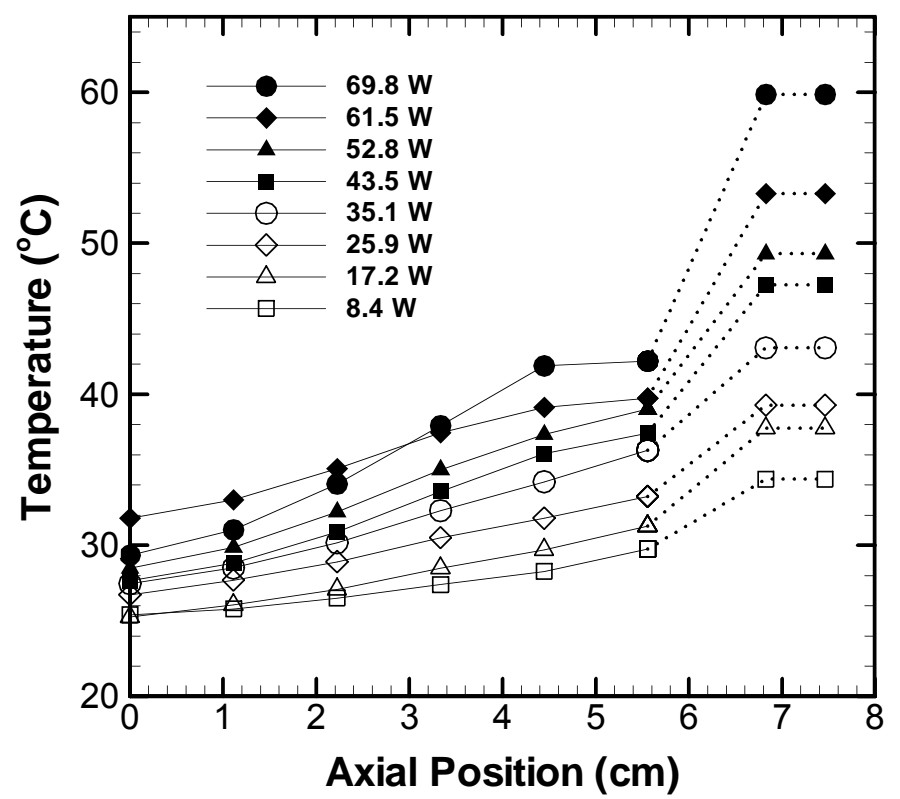

(a)

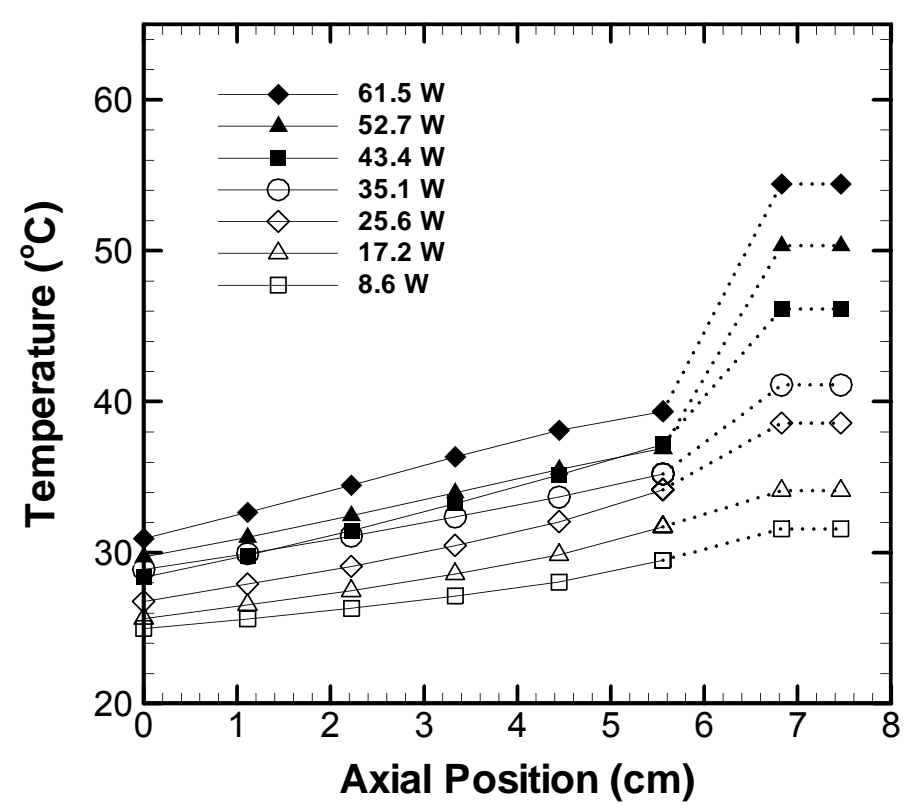

(b)

Figure 9 Temperature profiles for wicks (a) TCR1 and (b) TCR5 at various applied power settings. 


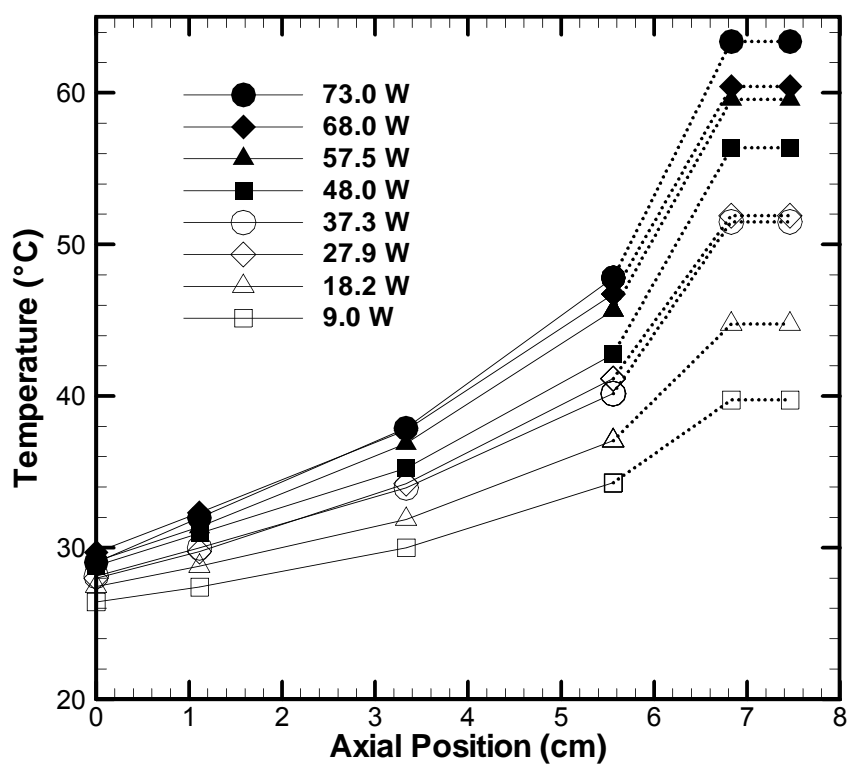

(a)

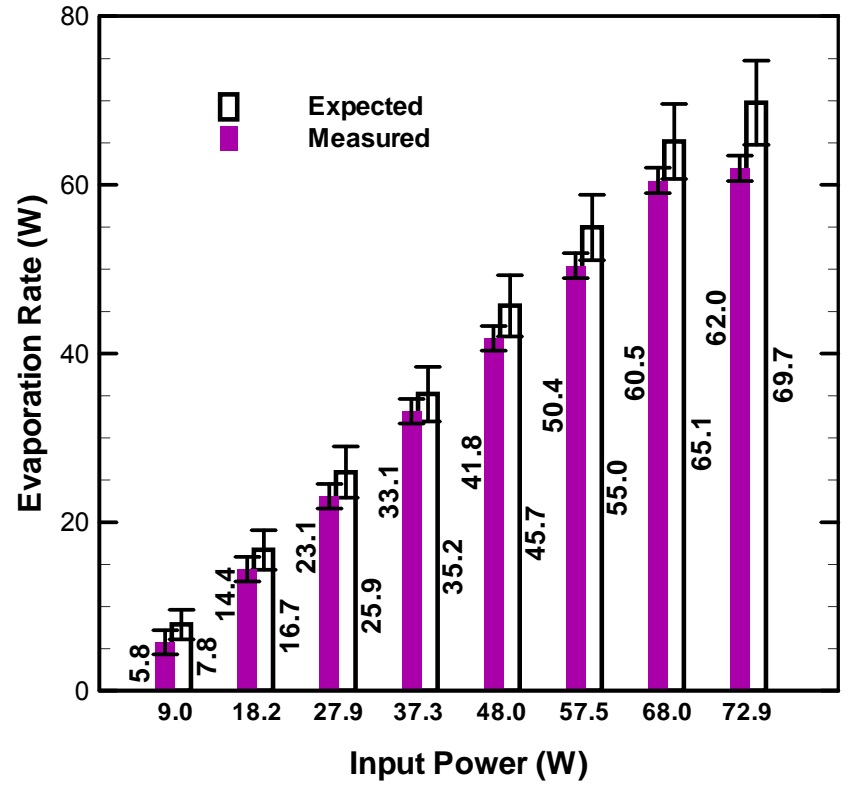

(b)

Figure 10 (a) Temperature profiles, and (b) measured and expected evaporation rates for wick BACK2. 


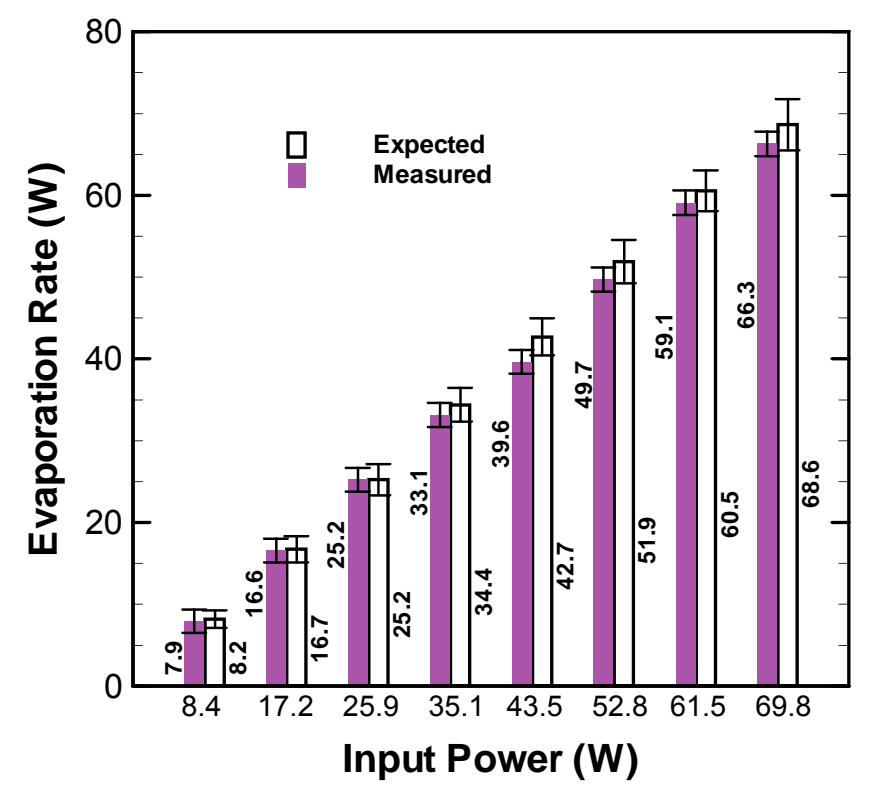

(a)

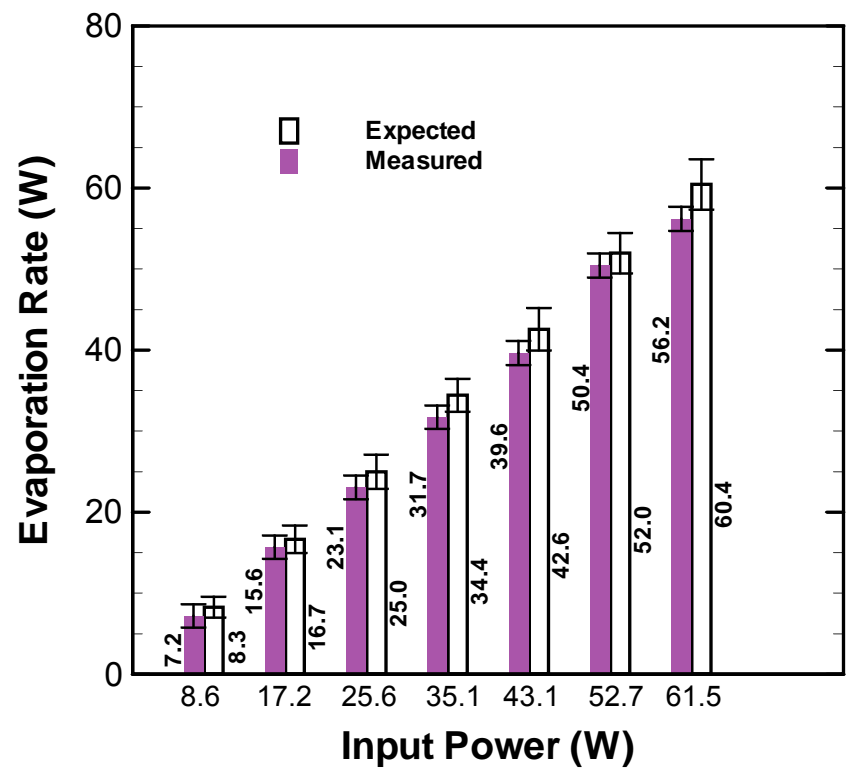

(b)

Figure 11 Measured and expected evaporation rates for wicks (a) TCR1 and (b) TCR5 at various input power levels. 


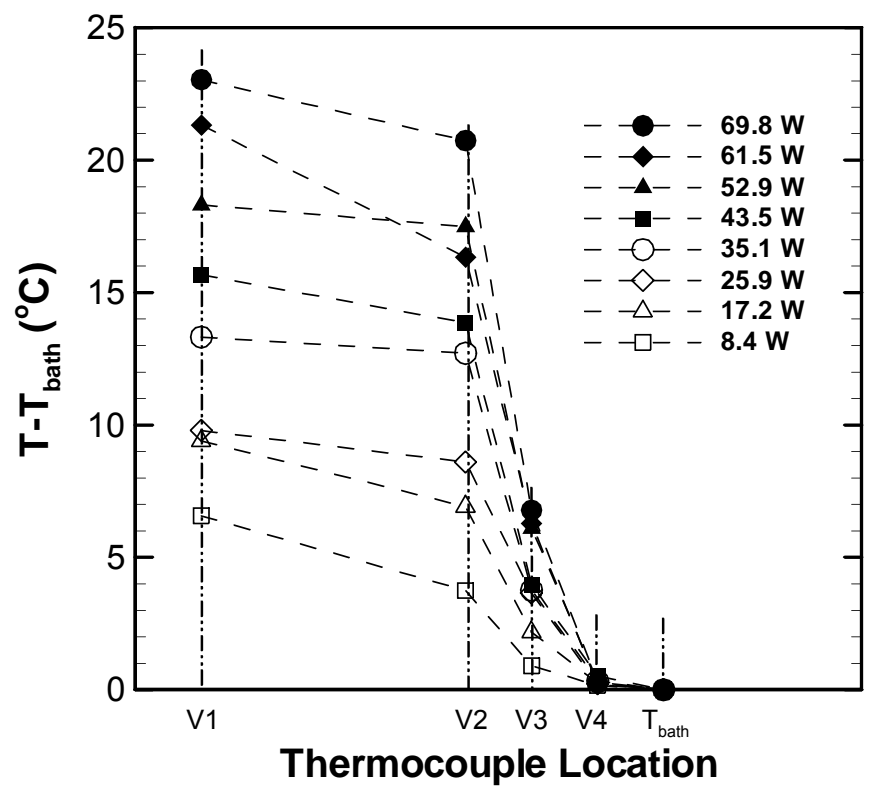

(a)

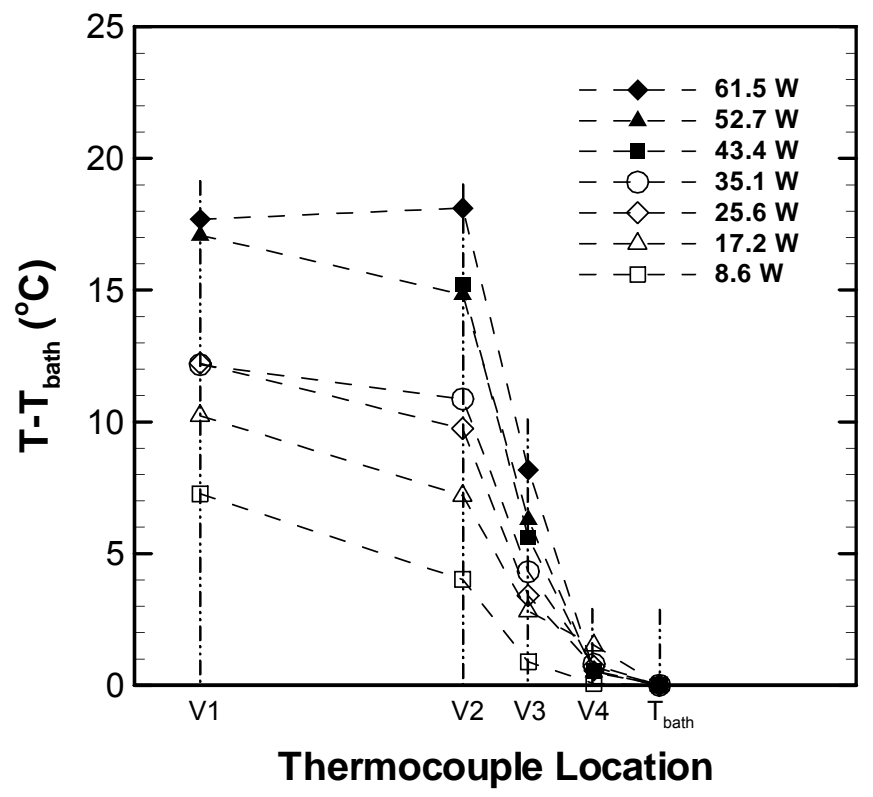

(b)

Figure 12 Vapor temperature map for (a) wick TCR1 and (b) TCR5 from wick front to condensate pool. Saturation temperatures $\left(T_{\text {sat }}-T_{\text {bath }}\right)$ vary from approximately 9 to $17^{\circ} \mathrm{C}$ for wick TCR1 and 11 to $15{ }^{\circ} \mathrm{C}$ for wick TCR5 as in Table 2. 


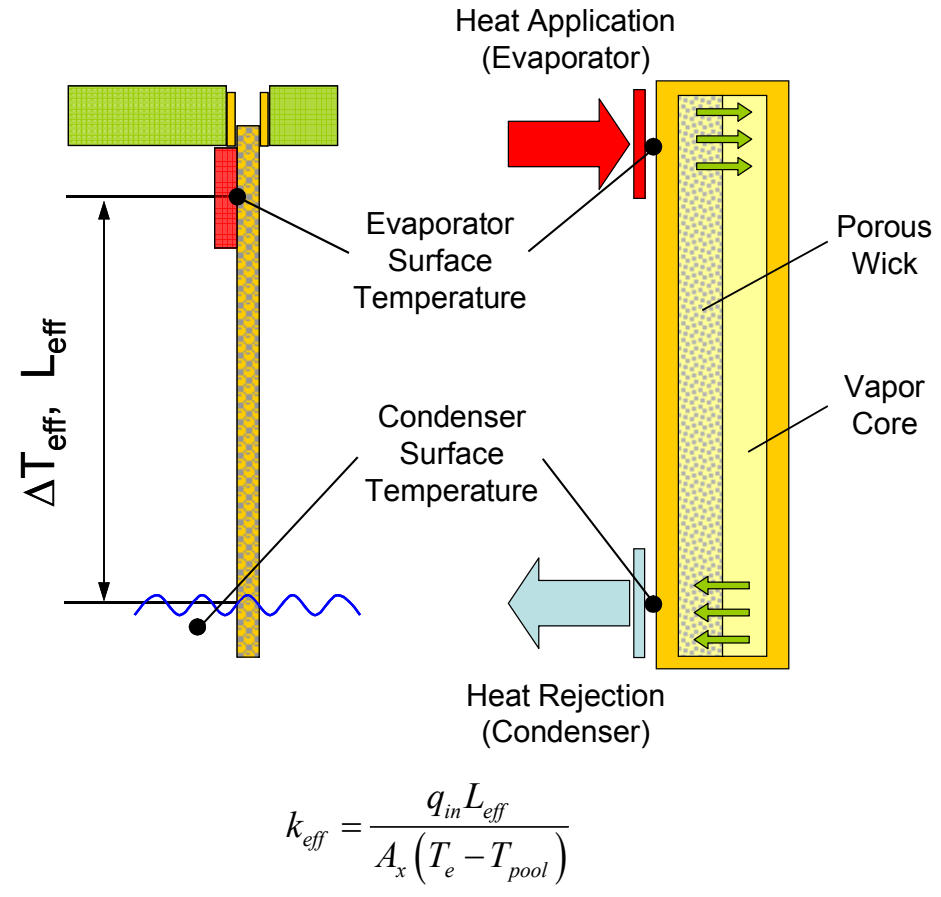

Figure 13 Criterion for calculation of overall effective wick conductivity $\left(k_{e f f}\right)$. 


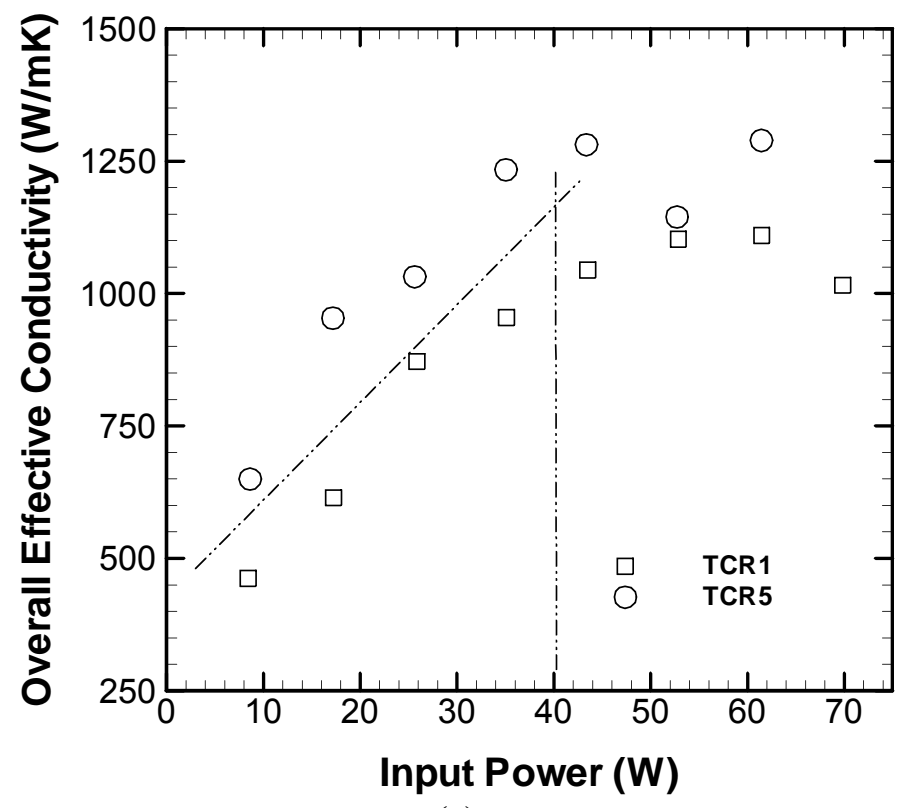

(a)

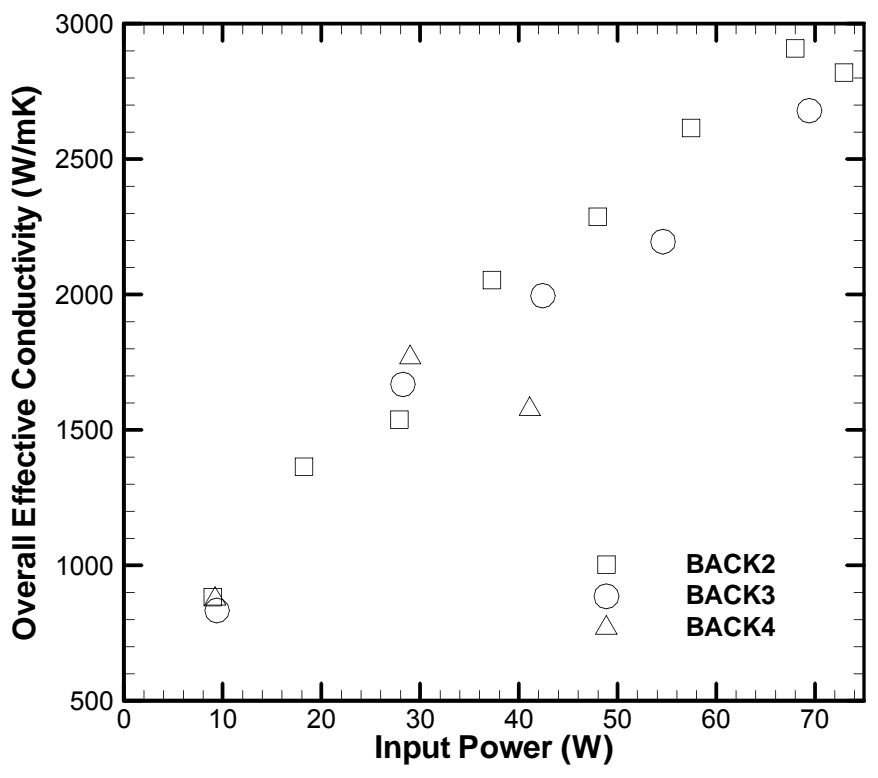

(b)

Figure 14 Overall effective conductivities for (a) TCR1 and TCR5, and (b) BACK2, BACK3 and BACK4 at various input power levels. 


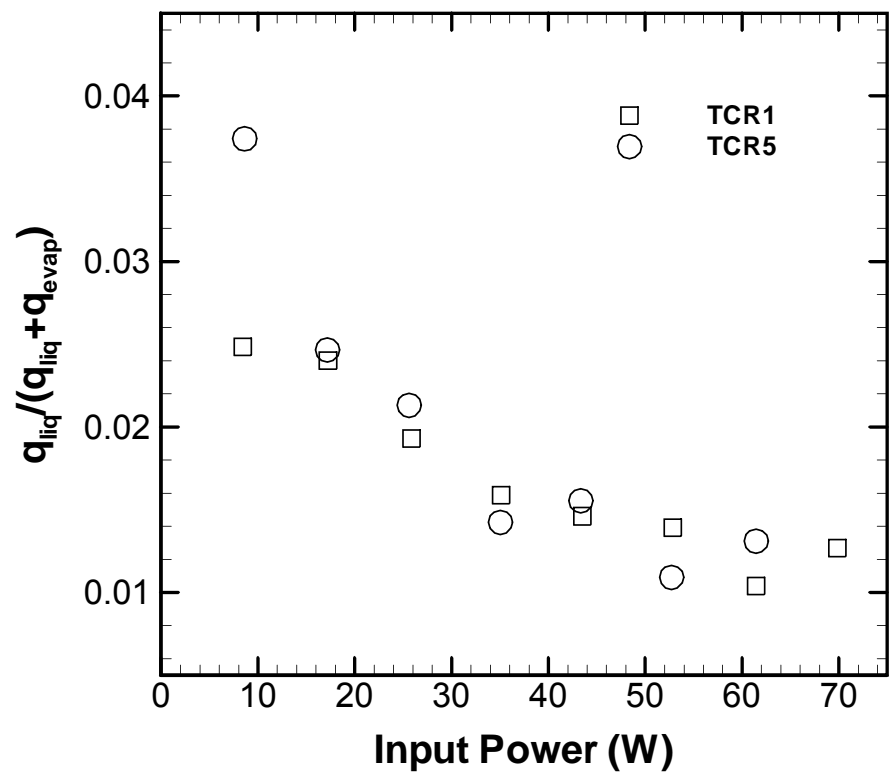

Figure 15 Normalized conduction rate into the liquid pool for TCR1 and TCR5 as a function of input power. 